\title{
Derivation of Kinematic Equations Based on Full-Scale Racking Tests for Seismic Performance Evaluation of Unitized Four-Sided Structural Sealant Glazing Curtain Wall Systems
}

\author{
Ali M. Memari ${ }^{1}$, Nicholas Simmons ${ }^{2}$ and Ryan L. Solnosky ${ }^{3, *(D)}$ \\ 1 Architectural Engineering and Civil and Environmental Engineering Departments, \\ The Pennsylvania State University, University Park, PA 16802, USA; amm7@psu.edu \\ 2 Simpson Gumpertz \& Heger (SGH), 480 Totten Pond Road, Waltham, MA 02451, USA; NCSimmons@sgh.com \\ 3 Architectural Engineering Department, The Pennsylvania State University, University Park, PA 16802, USA \\ * Correspondence: rls5008@psu.edu
}

check for updates

Citation: Memari, A.M.; Simmons, N.; Solnosky, R.L. Derivation of Kinematic Equations Based on Full-Scale Racking Tests for Seismic Performance Evaluation of Unitized Four-Sided Structural Sealant Glazing Curtain Wall Systems. Buildings 2021, 11,593. https://doi.org/10.3390/ buildings 11120593

Academic Editor: Elena Ferretti

Received: 12 September 2021

Accepted: 22 November 2021

Published: 28 November 2021

Publisher's Note: MDPI stays neutral with regard to jurisdictional claims in published maps and institutional affiliations.

Copyright: (c) 2021 by the authors. Licensee MDPI, Basel, Switzerland. This article is an open access article distributed under the terms and conditions of the Creative Commons Attribution (CC BY) license (https:// creativecommons.org/licenses/by/ $4.0 /)$.

\begin{abstract}
Curtain wall glazing systems are a major part of a building due to the multiple roles they have, including occupant protection against environmental effects and the transfer of loads to the structural system. From a structural perspective, limited analytical guidelines and methods exist to aid designers in their determination of the curtain wall performance without extensive simulation or laboratory testing. This study takes experimental data from full-scale, "unitized", four-sided structural sealant glazing (4SSG) curtain wall system mockups featuring a re-entrant corner subjected to cyclic racking displacements in accordance with the American Architectural Manufacturers Association AAMA 501.6 protocol to derive and establish equations that predict the relative displacements of the glass relative to the glazing frame, based on the amount of inter-story drift. Through derivation and testing, sealant cohesive failure and glass cracking were identified as limit states and corresponding drift levels were determined to control many of the equations. Displacements from the newly derived equations were correlated to the effective shear strain value experienced by the structural silicone in the mockup concurrently with the curtain wall's drift capacity. This paper provides detailed derivation of the kinematic equations for possible use by glazing design professionals. Such equations can help designers to more easily predict the drifts that cause damage to such systems by manual calculations without the need for expensive mockup testing or time-intensive computer models.
\end{abstract}

Keywords: unitized curtain wall systems; cyclic dynamic racking; kinematic response; four-sided structural sealant glazing

\section{Introduction}

In the absence of well-established analytical or numerical models, full-scale mockup testing is the main option for structural engineers and curtain wall designers, who need to evaluate the accurate value of system behavior and the response of "unitized" four-sided structural sealant glazing (4SSG) systems under seismic effects. The industry standard is to conduct full-scale mockup testing to evaluate the performance of curtain wall systems. For United States projects, procedures are prescribed in AAMA 501.4 and 501.6 guidelines [1]. AAMA 501.4 prescribes a statically applied in-plane lateral load to evaluate the air and water leakage rates if the system experiences a serviceability level earthquake loading and resulting damage. AAMA 501.6, however, is intended to evaluate the life-safe aspect after an ultimate level design earthquake, which will excite the inertial effect, thus it is considered a dynamic loading. For practical curtain wall design projects, AAMA 501.6 must be used if analytical or numerical methods are not readily available or feasible. In addition to AAMA 501.4 and 501.6, a JRC report developed in 2014 [2] prescribes recommendations for structural glass design with respect to the Eurocode. Several key 
attributes of AAMA and JRC are similar in determining the structural performance of curtain walls. References $[3,4]$ include some drawings and additional information about the application of AAMA standard tests.

For this research, large full-scale mockups need to be dynamically tested, which involves instrumentation and sensors as the standard method for collecting performance data $[5,6]$. While extremely beneficial to have experimental data that is precise, the cost and availability of sensors can lead researchers to collect limited data, along with the cost of the specimen, which limits the number of tests. This is particularly true when it comes to full-scale specimens $[7,8]$. To avoid expensive physical testing, for actual building design and construction projects, the development of prediction equations is necessary for designs to utilize. Being able to have prediction equations is significant since the AAMA 501.6 [1] testing process takes time and consumes resources that some firms and clients may not have at their disposal. These equations are intended to help design professionals in specifying 4SSG curtain wall systems and can lead to reducing the effort during curtain wall design stages.

Several studies characterize the seismic performance of curtain wall systems [9-13]. While there are a few contributions to developing prediction models/equations for dryglazed curtain wall systems, there are not many published works on kinematic design of SSG systems. Simmons and Memari [14] and Memari et al. [12] attempted to derive equations for the design of two-sided structural sealant glazing (2SSG) configurations for the prediction of failure drifts. This work presents the equivalent of such a study for 4SSG configurations.

Alternative to physical testing is finite element modeling (FEM) of architectural glass curtain wall systems. While closed-form equations are simple to use for manual calculations, as the structure and curtain wall system becomes more complex, there exists in designers a preference to use commercial software packages. There have been multiple numerical studies using FEM to study architectural glass curtain wall systems, in particular for point-supported glass systems [15-17] and cantilevered glass systems [18]. In 2016, ASTM [19] published a document that considers numerical methods using commercially available finite-element analysis software to determine stresses and deflections in glass lites. Of course, a study by Soules et al. [20] and Morse [21] points out that numerical methods discussed in [19] do not provide specific modeling guidance to ensure that the results from a finite-element analysis match similar results obtained from the chart-based method $[19,21]$.

This paper presents a portion of a broader study that involved racking testing, finite element modeling, and video capture techniques of curtain wall systems [14,22-24]. The objective of the study presented in this paper was to develop closed-form kinematic equations that help predict failure drift for different limit states for 4SSG curtain wall systems. This study, as presented here, establishes the development of experimentally validated derived kinematic equations based on full-scale racking tests with re-entrant corners. While these kinematic equations can be used in developing codes for ease designer calculations, the objective of this study was mainly to derive the needed equations, which can then be used in closed-form scenarios. In the interest of brevity to focus on kinematic derivation, discussions on numerical methods using FEM and video capture analysis are only briefly mentioned in Section 2. The overall layout of the paper consists of background and context, materials and system definitions, formulation of kinematic equations.

Both cohesive failure of the structural sealant (SS) and cracking of glass were chosen as the critical limit states, with the observed corresponding drifts determined from the full-scale mockups testing [24]. The derived equations would then permit an enclosure designer to calculate the effective shear strain in the SS at any drift demand, thus greatly improving their design process.

The purpose of developing kinematic-based equations is to identify key limit states that would be of interest to curtain wall design professionals. The equations would serve as a design guide, which would lead to a curtain wall design to have a better chance of not 
reaching the particular limit states during a racking test based on AAMA 501.6 [1]. These closed-form equations will allow a curtain wall designer to have an initial understanding of how a curtain wall design will behave without the need for finite element modeling (FEM) or physical testing. These equations are derived based on pure racking conditions, not the racking that would include a vertical slip or unitized sway conditions (also part of the study). In the derivation of the kinematic equations, failure of SS and contact of glass pane corners with adjacent glass panes were chosen as limit states. Due to these two different limiting behaviors, two different and independent prediction equations were developed. No effort was made to describe the behavior after SS failure or glass pane corner contact to the glass pane side.

\section{Summary Discussion of Physical Testing and Computational Modeling}

\subsection{Summary of Physical Testing of Curtain Wall Mockups}

To establish kinematic equations for designer adoption and use, first a series of physical tests of curtain wall mockups were performed as part of a larger project. Here, the overall research goal was to determine the failure limit states of unitized curtain wall systems, where the glass and sealant are vulnerable to failure under seismic induced racking. Part of this objective was to determine the glass cracking and fallout limit states along with cohesive and adhesive failure in the sealant (should it occur). Once the drift associated with such failures is known, curtain wall designers can detail the systems to avoid such failures. Memari et al. [24] and Simmons [25] provide details of the physical testing program with key highlight summaries of constants, variables, and observations from the physical tests that were used to help validate as well as generate the kinematic equations in this paper.

The racking facility shown in Figure 1 consists of two steel tubes that slide in opposite directions creating an inter-story drift that will cause the attached curtain wall system to rack and with increased amplitudes reveal potential failure modes. The racking protocol consisted of applying actuator displacements steps including four ramp-up cycles followed by four constant-amplitude and ending with another four cycles of ramp-down cycles.

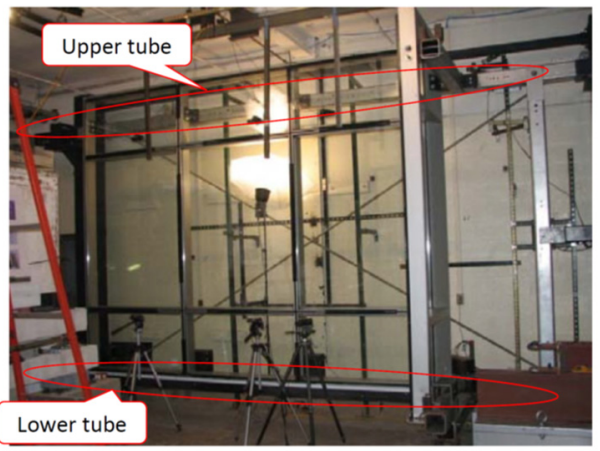

Figure 1. BECRL racking test facility with a mounted mockup.

Two sets of identical mockups referred to here as mockups B and C were built that are glazed with Dow Corning 983 Structural Glazing Sealant. The basic dimensions of the mockups are shown in Figure 2, while Figure 3a-c show boundary conditions for mockup with (1) sway, (2) racking with vertical sway, and (3) pure racking movements. The difference between mockups $B$ and $C$ are the boundary conditions, with mockup $B$ having conventional stick-built boundary condition, while mockup $C$ is similar to mockup $B$ but allows vertical slip. Given these slight differences, mockup B resembles a more pure-racking behavior, whereas mockup $C$ allowed for the panels to slip vertically past each other. 


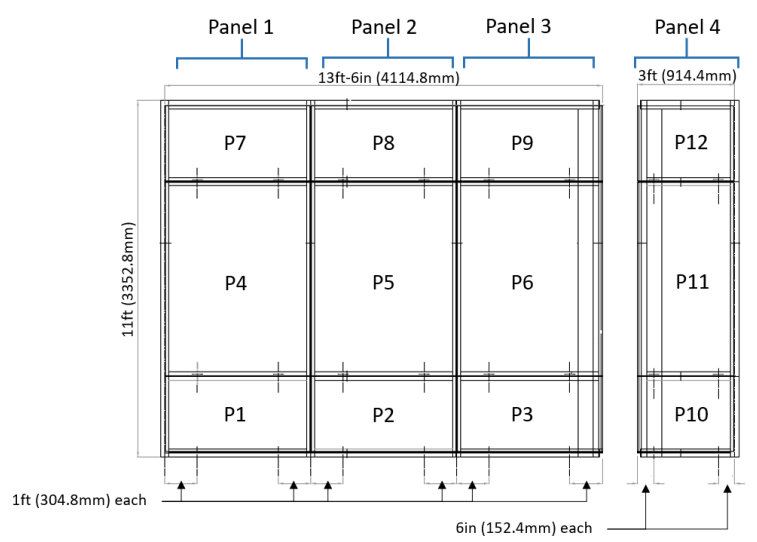

(a)

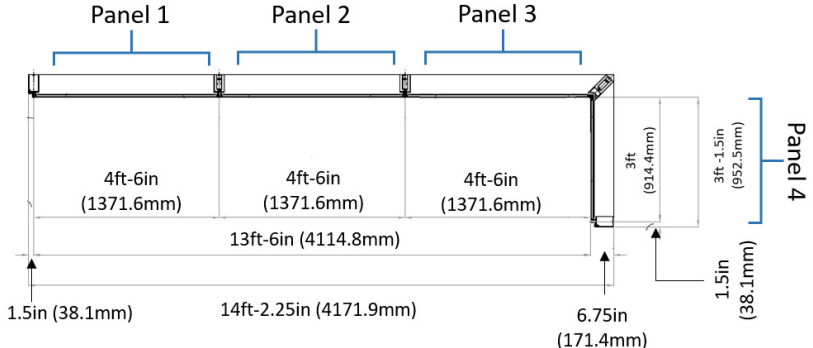

(b)

Figure 2. Layout of panels of a 4SSG curtain wall system. (a) Elevation views of the panels; (b) plan view of the panels (Note that: 1 in. $=25.4 \mathrm{~mm} ; 1 \mathrm{ft}=304.8 \mathrm{~mm}$ ).

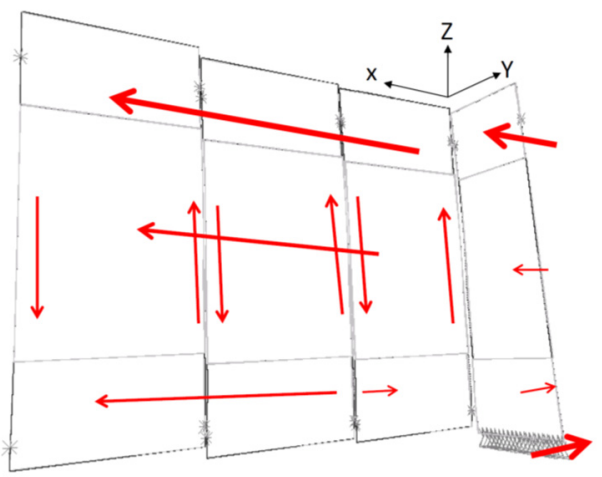

(a)

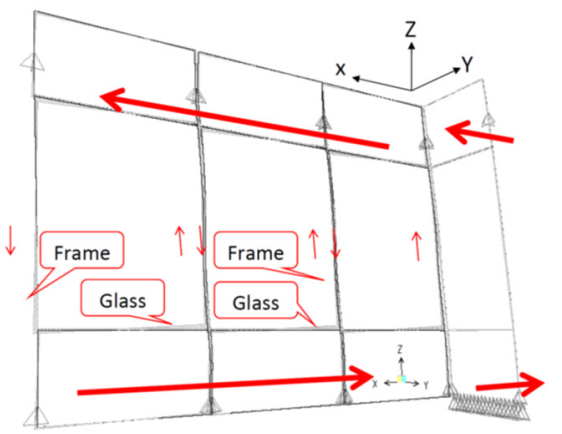

(c)

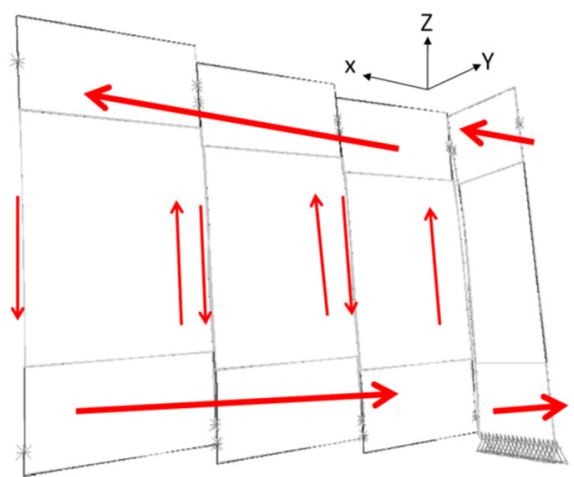

(b)

Figure 3. Panel configuration of frame and glass (frame = dashed lines, glass panes = solid lines). (a) Mockup with sway boundary conditions; (b) mockup with rack with vertical slip boundary condition; (c) mockup with pure racking boundary condition.

Each mockup was tested according to the displacement-controlled racking protocol recommended in AAMA 501.6 [1], which characterizes monotonically increasing amplitude sinusoidal drift cycles. AAMA 501.6's "stepwise" test method requires a series of alternating "ramp up", "constant amplitude", and "ramp down" intervals, each comprised of four sinusoidal cycles where each step increases by $1 / 4$ in. $(6.4 \mathrm{~mm})$ increments. These loading steps simulate the cyclic, in-plane racking dynamic behavior of earthquakes that are to be used in the determination of the serviceability and ultimate drift limits for architectural glass components [24]. During each test, the racking movement was stopped after each $1 / 4$ in. $(6.4 \mathrm{~mm})$ step for inspection of any structural sealant damage. Figure 4 
depicts this drift vs. time for Step 12 (maximum nominal amplitude of $3 \mathrm{in} .(76.2 \mathrm{~mm}$ )). Additionally, Figure 4 depicts both the positive and negative drift amplitudes imposed on the mockup during the sixth cycle (as labeled as C6.25 and C6.75). These two points indicate the targeted moments to study in the video analysis [26].

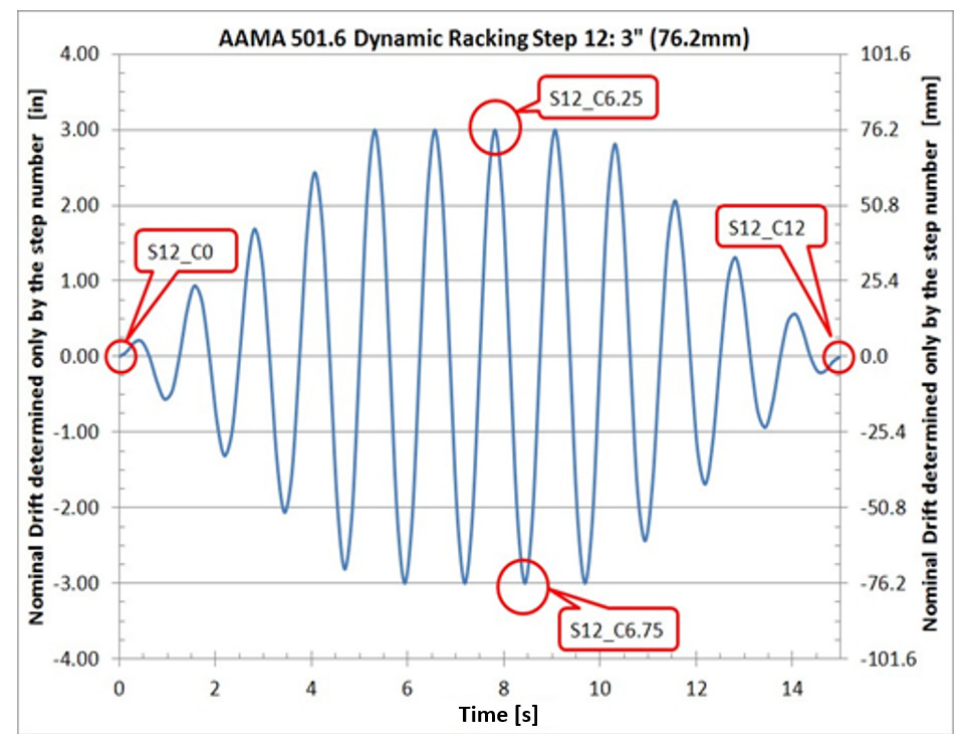

Figure 4. Dynamic racking drift vs. time plot at Step 12 (based on AAMA 501.6 protocol [5]). (Note that: 1 in or $1^{\prime \prime} .=25.4 \mathrm{~mm}$ ).

The testing is reported for two identical mockups B and C. The observed failure modes are similar to those presented in Memari et al. $[9,11,26]$. Mockups B and C were each tested twice to study the effect of varying boundary conditions per Table 1's documented changes. First, mockups B and C were tested with a unitized sway condition. After assessing the damage conditions of both, they were determined to be in acceptable condition for further testing of boundary condition set 2 . Changes included mockup B was now tested with stick-built boundary condition, while mockup $C$ was then tested with the stick-built with the vertical-slip condition.

Table 1. Physical experiment testing matrix for boundary conditions and connections.

\begin{tabular}{ccccc}
\hline $\begin{array}{c}\text { Mockup } \\
\text { Number }\end{array}$ & Test Number & $\begin{array}{c}\text { Boundary } \\
\text { Condition }\end{array}$ & $\begin{array}{c}\text { Upper } \\
\text { Connection }\end{array}$ & $\begin{array}{c}\text { Lower } \\
\text { Connection }\end{array}$ \\
\hline B & 1 & Sway & $\begin{array}{c}\text { Two separate } \\
\text { bolts with angles }\end{array}$ & No connection \\
\hline B & 2 & Racking & $\begin{array}{c}\text { Two separate } \\
\text { bolts with angles }\end{array}$ & $\begin{array}{c}\text { One bolt with } \\
\text { two angles (one } \\
\text { each side) }\end{array}$ \\
\hline C & 1 & Sway & $\begin{array}{c}\text { Two separate } \\
\text { bolts with angles }\end{array}$ & No connection \\
\hline C & 2 & Racking with & $\begin{array}{c}\text { Two separate } \\
\text { bolts with angles }\end{array}$ & $\begin{array}{c}\text { Two angles (one } \\
\text { each side no bolt }\end{array}$ \\
\hline
\end{tabular}

Note: All boundary conditions for mockups B and C have no weather seals.

The testing of mockup B and C provided the necessary numerical data for validation of other performance methods that were studied such as video capture, finite element modeling, and kinematic approach that this paper focuses on. While this paper is focused only on the kinematic relations derivation, a brief explanation of the video capture and finite element modeling is provided. 


\subsection{Summary of Video Capture Technique}

Concurrent with the physical testing, video recordings of the tests were taken. The video capture method [26] was developed as an alternative to using extensive sensors and instrumentation to determine drifts corresponding to failure conditions for 4SSG systems. The video capture method was established using video capture framed stills (e.g., Figure 5) to determine relative movement between glass edge and framing. Using the frames, the effective shear strain of the structural silicone was able to be calculated. Nine hand-held video camcorders were aimed at the intersections of each panel (Figure 6). Focal area locations L1, L2, and L3 were mounted to the ceiling, while locations L4 to L9 were mounted on tripods at the respected height away from the test. To ensure straight-on views, all the camcorders were leveled using a digital level. After the tests were completed, two different video capture and image measurement techniques were implemented. Each technique sought to measure the movement of the glass corners relative to the mullions and transom. The first technique took frame-by-frame shots of the intersection of joints (L1-L9) that completed measurements looking for the maximum and minimum movements. These isolated frames were then properly scaled and measure in AutoCAD. The second technique used CMA Coach 6 Studio MV's application Data Video that point tracked key joint locations over a series of frame intervals. Videos consisted of 450-900 frames that there were analyzed.
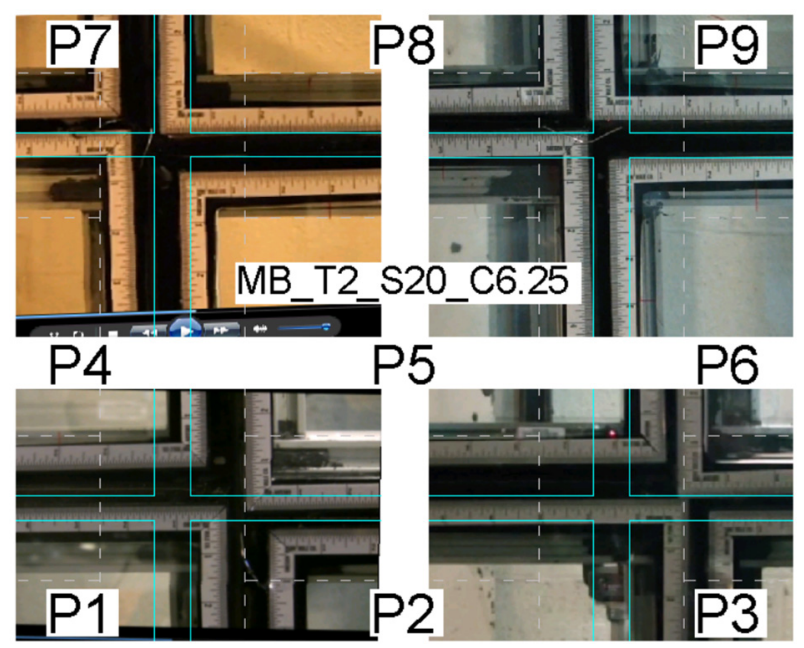

Figure 5. Example snapshot of video capture of glass panels movements at a corner along with deformation of weather seals.
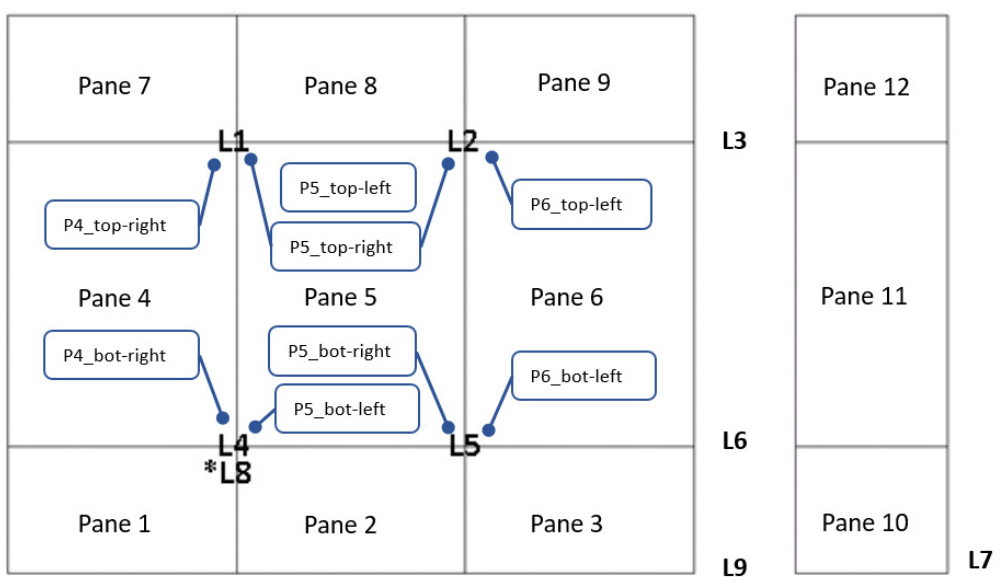

Figure 6. Video analysis area of focal areas for cameras. 


\subsection{Summary of Finite Element Modeling}

The most relied upon approach to determine the stress distribution within a given structure in practice is through FEM, which was also used in this study [23] to establish a modeling approach suitable for 4 SSG systems. Based on the displacements obtained from FEM, the effective shear strain of the structural silicone was determined, which would help define the failure conditions.

For this study, SAP2000 was used to develop the FEM similar to what curtain wall designers might utilize. Due to the complexity of curtain wall systems, including 4SSG configurations, the FEM was created in multiple steps. These steps included: (1) exclusively model individual elements, (2) model other portions of the system, and finally (3) model the entire system in great detail. For this research study, the FEM was created using a combination of frame, area, and link elements within SAP 2000 that follows simplified assumptions to more accurate modeling for three distinct models.

Three models were created [25]: (1) a single-panel curtain wall consisting of three glass panes, modeling only the stick-built support condition, (2) a three-panel curtain wall where each panel has three glass panes that are in the racking plane with vertical mullions being treated as continuous whereas the horizontal transoms are modeled as non-continuous, and lastly, (3) a complete 4SSG system of the mockup consisting of three planar panels and one perpendicular panel to form a 3D model with the reentrant corner. To have noncontinuous horizontal transoms, ends were modeled as having a pin connection or partial fixity (depending on the model). To create this model, first, the unitized sway support condition was modeled, considering two verifications: (1) comparing system stiffness with the hysteresis data from physical testing, and (2) comparing glass pane corners movement relative to the frame from the video analysis data.

The assigned FEM boundary conditions (Figure 7) are the only distinction between the mockups that needed special consideration across the models. Table 2 details the assumed restraints (R1 through R17). R9 to17 remain consistent for each FEM, while R1 to R8 vary (Figure 7). A uniform displacement was modeled at restraints R9 through R 16 in the $\mathrm{X}$-direction. From the analysis, reactions at each of the restraints are able to be pulled. Restraints R9 to R17 reaction forces were considered equal then applied as loads to the system. The directionality of the respective loads as the locations are as follows: the UX DOF is released for R9 to R17 so that only UY and UZ are restrained from movement.

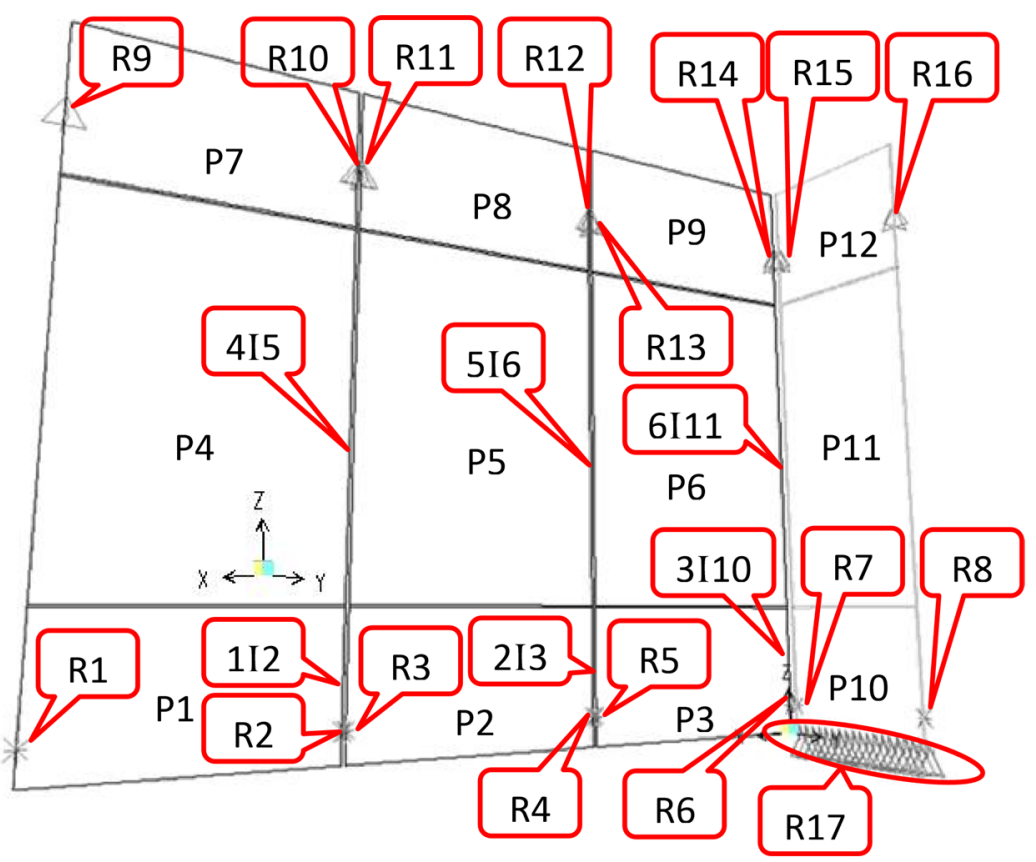

Figure 7. Three-dimensional (3D) perspective view of un-deformed mockup. 
Table 2. Restrained translation DOF's as defined in SAP2000 FEM for each test [25].

\begin{tabular}{cccc}
\hline & \multicolumn{3}{c}{ Direction of the Restrained DOFs * } \\
\cline { 2 - 4 } Restraint \# & $\begin{array}{c}\text { Mockup: MB_T1 } \\
\text { and MC_T1 }\end{array}$ & Mockup: MC_T2 & Mockup: MB_T2 \\
\cline { 2 - 4 } & Unitized Sway & $\begin{array}{c}\text { Rack with Vertical } \\
\text { Slip }\end{array}$ & Rack \\
\hline R1 to R5 & $\mathrm{Y}$ & $\mathrm{X}, \mathrm{Y}$ & $\mathrm{X}, \mathrm{Y}, \mathrm{Z}$ \\
\hline R6 & $\mathrm{Y}$ & $\mathrm{Y}$ & $\mathrm{X}, \mathrm{Y}, \mathrm{Z}$ \\
\hline R7 to R8 & None & None & $\mathrm{X}, \mathrm{Y}, \mathrm{Z}$ \\
\hline R9 to R16 & $\mathrm{X}, \mathrm{Y}, \mathrm{Z}$ & $\mathrm{X}, \mathrm{Y}, \mathrm{Z}$ & $\mathrm{X}, \mathrm{Y}, \mathrm{Z}$ \\
\hline R17 & & $\mathrm{X}, \mathrm{Y}, \mathrm{Z}$ are all restrained \\
\hline *See Figure 3 for definition of X, Y, and Z directions.
\end{tabular}

* See Figure 3 for definition of $X, Y$, and $Z$ directions.

\section{Materials and Methods for Kinematic Equation Derivation}

As part of the kinematic equation derivation, two limit states were considered in the development based on observed behaviors. Condition one was based on the structural sealant (SS) failure limits. Condition two was based on corner contact between two adjacent glass panes. Because these are distinctly different limiting conditions, prediction equations were developed consistent with these failure conditions.

\subsection{Definition of Parameters and Assumptions for Derivation of Equations}

From the physical testing and resulting video analysis conducted by Memari et al. $[24,26,27]$, data revealed that there were distinct translations and rotations of the glass panes with respect to the adjacent aluminum mullions. An example detail of the connection of the transom to mullion is shown in Figure 8. To establish the equations, global coordinates of the X-direction are horizontal, the Y-direction is out of the plane, and the Z-direction is vertical were proposed. To simplify derivation, individual glass panes were designated at each row of the mockup (Figure 2). The bottom-most row in the plane was Row 1 with panes P1, P2, and P3; The middle in the plane row was Row 2 with panes P4, P5, and P6; and the top row was labeled as Row 3 with panes P7, P8, and P9. These nine panes were assumed to have three features: (1) panes were free to translate in the horizontal direction, (2) panes were free to translate in the vertical direction, and lastly, (3) panes were free to rotate approximately the same amount based on their size and gaps between panels (Figure 9). In the equation development, the mockup's perpendicular re-entrant corner (Figure 9) was ignored in the derivation of the equation to simplify the geometry, while the out-of-plane connections stayed flexible.

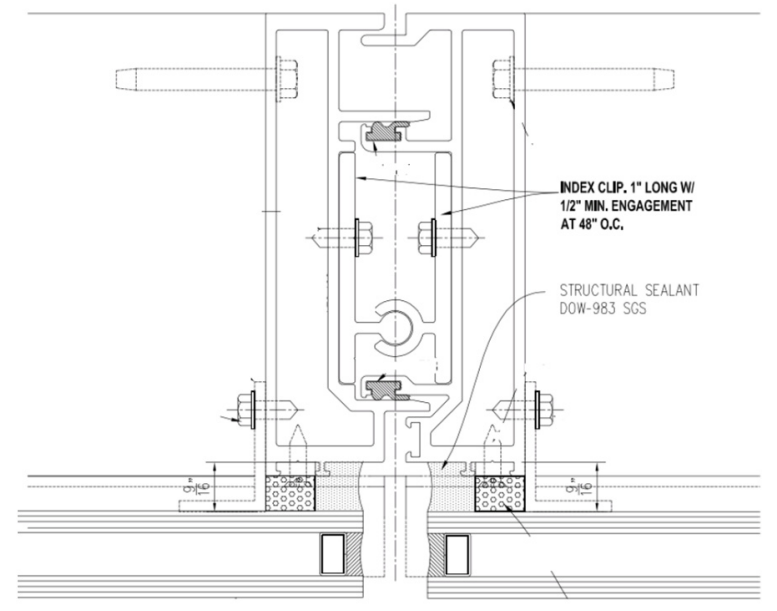

Figure 8. Example detail for mullion to transom connection. 


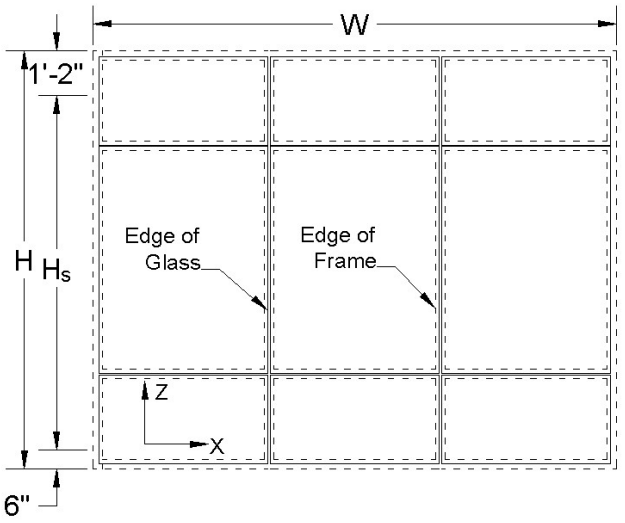

(a)

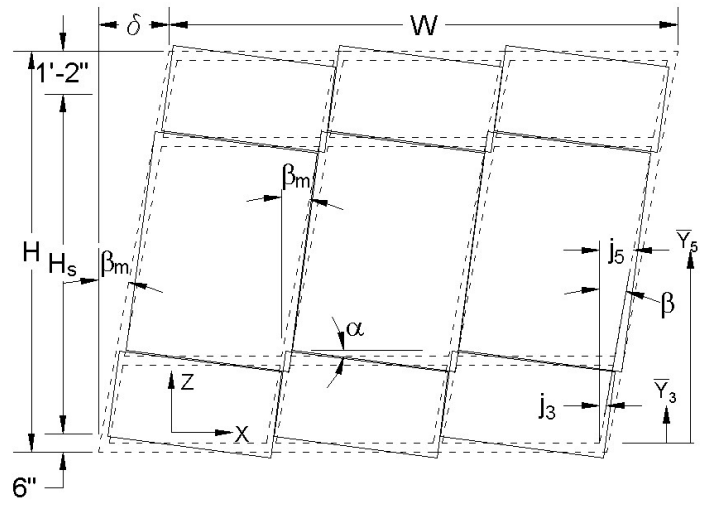

(b)

Figure 9. Panel configuration of frame and glass (frame = dashed lines, glass panes = solid lines). (a) Un-deformed shape; (b) deformed shape.

Each glass pane has a rotation $(\alpha)$ of with respect to an initial condition (represented as $\alpha_{\mathrm{n}}$, with $\mathrm{n}$ referring to the glass pane number). $\beta_{\mathrm{m}}$ is defined as the mullion rotation. Transom rotation and the transom change in slope is designated as $\beta_{\mathrm{t}}$, but it was observed to be relatively small, and therefore, in this study taken as zero for the stick-built condition equations. Curtain wall inter-story drift $(\delta)$ is considered over the full height of the mockup $(\mathrm{H})$. The applied mockup drift $\left(\delta_{\mathrm{s}}\right)$ was placed along a height $\left(\mathrm{H}_{\mathrm{s}}\right)$ that correspond to the distance from the upper and lower sliding tubes of the experimental facility. Rotation values $\beta_{\mathrm{t}}, \beta_{\mathrm{m}}$, and $\alpha$ were determined from both video analysis [22,24] and FEM [21] of each mockup with an applied inter-story drift of $1.99 \mathrm{in}$. (50.55 mm). Simmons [25] and Memari et al. [24] detail the results of the investigations with key summary findings provided in Table 3. Another variable is the coefficient $c_{\text {angle, }}$ which represents the glass pane rotation divided by the theoretical mullion rotation $\left(\delta_{\mathrm{m}}\right)$. From the mockup geometry, $\beta_{\mathrm{m}}$ is the applied drift of the mockup $\left(\delta_{\mathrm{s}}=-1.99 \mathrm{in}\right.$. $\left.(50.55 \mathrm{~mm})\right)$ divided by the vertical distance between the boundary conditions of the test $\left(\mathrm{H}_{\mathrm{s}}\right.$ the tests is $=109 \mathrm{in} .(2769 \mathrm{~mm})$ ).

Table 3. Measured glass pane rotations in stick-built mockup at S12_C6.75 (adapted from [23]).

\begin{tabular}{ccccc}
\hline $\begin{array}{c}\text { Pane Location } \\
\text { (Pane Number } \\
\text { and Row) }\end{array}$ & $\begin{array}{c}\text { Video Analysis } \\
\text { Results }\end{array}$ & FEM Results & $\begin{array}{c}\text { Average of } \\
\text { Video } \\
\text { Analysis and } \\
\text { FEM Results }\end{array}$ & c $_{\text {angle Value }}$ \\
\hline $\begin{array}{c}\text { P7, P8, P9 in } \\
\text { Row 3 }\end{array}$ & $-0.00179 \mathrm{rad}$ & $-0.00573 \mathrm{rad}$ & $-0.00376 \mathrm{rad}$ & 0.206 \\
\hline $\begin{array}{c}\text { P4, P5, P6 in } \\
\text { Row 2 }\end{array}$ & $-0.00721 \mathrm{rad}$ & $-0.01241 \mathrm{rad}$ & $-0.00981 \mathrm{rad}$ & 0.537 \\
\hline $\begin{array}{c}\text { P1, P2, P3 in } \\
\text { Row 1 }\end{array}$ & $-0.00432 \mathrm{rad}$ & $-0.00383 \mathrm{rad}$ & $-0.00407 \mathrm{rad}$ & 0.223 \\
\hline
\end{tabular}

\subsection{Mullion and Glass Pane Rotation and Movement Derivation}

Figures 10 and 11 show the horizontal distance (r) and vertical distance (s) measured from the nearest interior mullion corner over to the glass corner. The designations shown in Figure 5 follow the following notation of r\#_C\# and s\#_C\# where the first number refers to the glass pane number and identifies the corner with letters $B=$ bottom, $T=$ top, $\mathrm{L}=$ left, and $R=$ right (Figure 11). The second number indicated with $C$ refers to the cycle of the step in the experimental procedure of AAMA 501.6. To easily describe the relative movement of the glass corners with respect to the mullions and transoms, step number is 16 data, and configuration of the structural sealant deformation of the was used unless noted otherwise. 


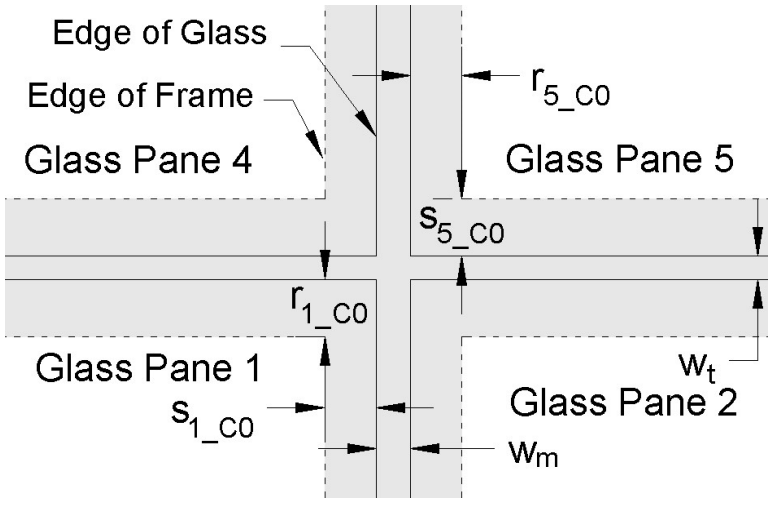

(a)

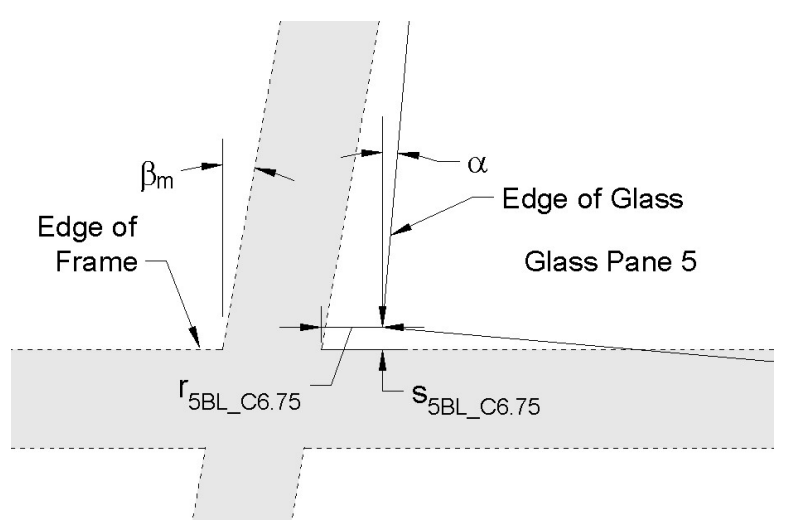

(b)

Figure 10. Movement and rotation notation for the frame and the glass pane at a corner; (a) un-deformed corner; (b) deformed corner.

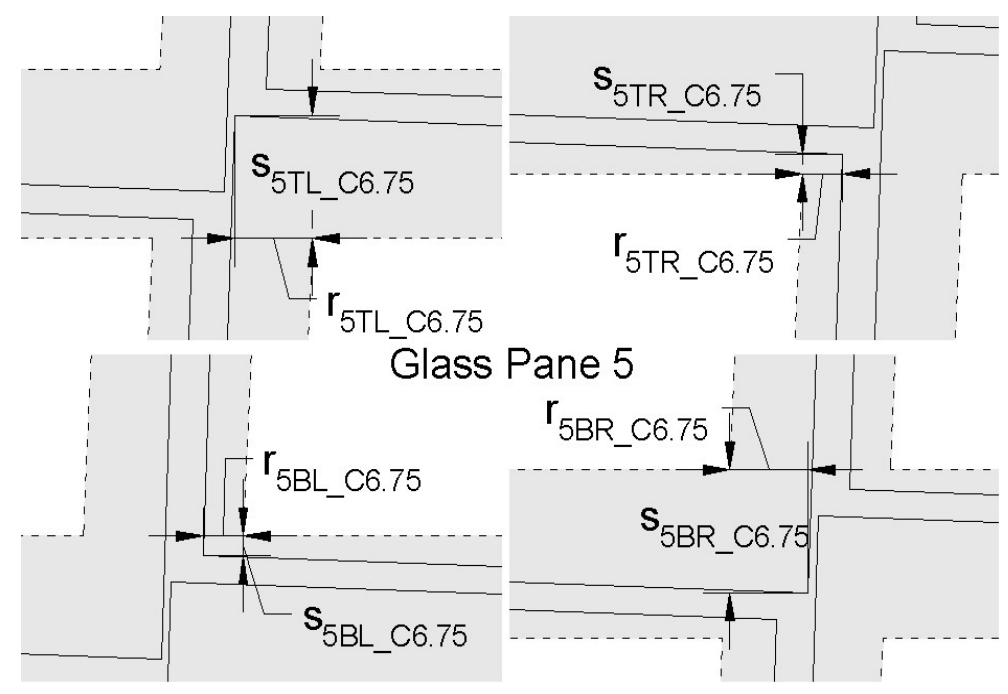

Figure 11. Glass pane 5 geometric rotation representation and notation of the four corners where the frame is dashed and the glass pane is solid.

$\beta_{\mathrm{m}}$ may be approximated by Equation (1). Here, $\beta_{\mathrm{m}}$ is largest when $\delta=6$ in. (152.4 mm). For the given mockups, the upper limit of $\beta_{\mathrm{m}}$ was found to be 0.04542 rads. Given the side of the curtain wall, $\beta_{\mathrm{m}}$ is considered a relatively small angle since the value may be approximated as $6 / 132 \mathrm{in}$. (50.55/3353 mm). All other angles for the derivations are expected to be smaller than $\beta_{\mathrm{m}}$. Thus, all equations will be simplified according to the small-angle approximation in the calculations. Equation (1) may then be solved for the drift giving Equation (2) where the distance between the boundary condition supports is $\mathrm{H}_{\mathrm{s}}$.

$$
\begin{gathered}
\tan \beta_{\mathrm{m}}=\frac{\delta}{\mathrm{H}} \\
\delta_{\mathrm{s}}=\beta_{\mathrm{m}} \mathrm{H}_{\mathrm{s}}
\end{gathered}
$$

In addition, $\alpha$ correlates to the deformation of the SS along the transom. The difference between $\alpha$ and $\beta$ correlates to the deformation of the SS along the mullion. The relationship between $\alpha$ and $\beta_{\mathrm{m}}$ was approximated as a linear relationship using a coefficient, $\mathrm{c}_{\text {angle }}$ as shown in Equation (3). Substituting Equation (3) into Equation (2) gives Equation (4).

$$
\alpha=c_{\text {anlge }} \beta_{\mathrm{m}}
$$




$$
\delta_{\mathrm{s}}=\frac{\alpha}{\mathrm{c}_{\mathrm{anlge}}} \mathrm{H}_{\mathrm{s}}
$$

Another assumption taken is that the transom only translates along the X-direction, while its flexural deformation is neglected due to the shear deformation of the SS being the dominant behavior. As a result, the global rotation of the glass pane is equal to the rotation relative to the transom. This relationship leads to Equation (5) in which, $\Delta \mathrm{s}_{5 \mathrm{BL}}$ and $\Delta \mathrm{s}_{5 \mathrm{BR}}$ are the changes in vertical measurements from the glass pane corner to the reference point at each end of the transom. Equation (5) shows that $\Delta \mathrm{s}_{5 \mathrm{BL}}$ is equal to $\Delta \mathrm{s}_{5 \mathrm{BR}}$. For simplification, both of these will be referred to as $\Delta \mathrm{s}_{5 \#}$ (Equation (6)). The character "\#" is used throughout this paper to generalize the sub-coefficients, and in this case \# $=B L=B R$.

$$
\begin{gathered}
\tan \alpha=\alpha=2 \frac{\Delta_{\mathrm{S} 5 \mathrm{BL}}}{\mathrm{w}_{5}}=2 \frac{\Delta_{\mathrm{S} 5 \mathrm{BR}}}{\mathrm{w}_{5}} \\
\Delta_{\mathrm{S} 5 \mathrm{BL}}=\Delta_{\mathrm{S} 5 \mathrm{BR}}=\Delta_{\mathrm{S} 5 \#}
\end{gathered}
$$

As part of the derivation, expressions for glass corner movement (displacement and rotation), references will be made back to Figures $9-11$ labeling. $\Delta s_{5 \#}$ is the difference between $\mathrm{S}_{5 \#+C 6.75}$ and $\mathrm{s}_{5 \#+} \mathrm{C} 0$ and consists of the vertical movement of the glass corner due to rotation, $\mathrm{e}_{5 \#+C 6.75}$ and the vertical translation of the glass, $\mathrm{k}_{5 \#+C 6.75}$, as shown in Equation (7). The expression for corner rotation as the difference between $\mathbf{r}_{5 \#+C 6.75}$ and

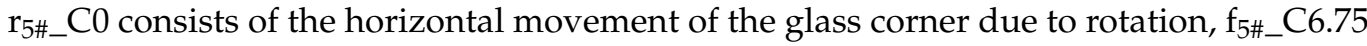
and the horizontal translation of the glass $j_{5 \#+} 66.75$, as represented by Equation (8).

$$
\begin{gathered}
\Delta_{\mathrm{S} 5 \mathrm{~B} \#}=\mathrm{S}_{5 \# \_c 6.75}-\mathrm{S}_{5 \# \_c 0}=\mathrm{S}_{5 \# \_c 6.7}+\mathrm{k}_{5 \# \_c 6.75} \\
\Delta_{\mathrm{r} 5}=\mathrm{r}_{5 \# \_c 6.75}-\mathrm{r}_{5 \# \_c 0}=\mathrm{f}_{5 \# \_c 6.75}+\mathrm{j}_{5 \# \text { _c6.75 }}
\end{gathered}
$$

Substituting Equation (5) into Equation (4) leads to Equation (9).

$$
\delta_{\mathrm{s}}=\frac{\alpha}{c_{\text {anlge }}} \mathrm{H}_{\mathrm{s}}=2 \frac{\Delta_{\mathrm{S} 5 \#}}{\mathrm{w}_{5}} \times \frac{\mathrm{H}_{\mathrm{s}}}{c_{\text {anlge }}}
$$

Since the mullion is expected to rotate and to deform due to shear and flexure, the relative movement of the mullion is more complicated. The kinematic model shown in Figure 12 represents the combination of rotation, shear deformation, and flexural deformation as an equivalent pure rotation. The equivalent shape is sufficient to portray the deflections at the corners of the glass panes. The global rotation of the mullion $\left(\beta_{\mathrm{m}}\right)$ minus the global rotation of the glass pane $(\alpha)$ represents the relative rotation of the glass pane $\left(\beta_{\mathrm{m}}-\alpha\right)$. Figure 12 shows a kinematic model of glass pane 5 for the top-left (TL) corner and bottom-left (BL) corner, in which $\Delta \mathrm{g}_{\mathrm{f}}$ is the horizontal distance between the top and bottom corners of a rotated glass pane, and $\Delta \mathrm{m}_{\mathrm{f}}$ is the horizontal distance between the top and bottom corners of a deflected mullion.

$\Delta \mathrm{g}_{\mathrm{f}}$ is the sum of the horizontal movement of the glass pane corner at the bottom, $\Delta_{\mathrm{r} 5 \mathrm{BL}}$ and the horizontal movement of the glass pane corner at the top, $\Delta \mathrm{r}_{5 \mathrm{TL}}$. Substituting Equation (8) into this relation gives Equation (10). Next, Equation (11) is derived based on the relationship shown in Figure 7.

$$
\begin{gathered}
\Delta \mathrm{g}_{\mathrm{f}}=\Delta \mathrm{r}_{5 \mathrm{BL}}+\Delta \mathrm{r}_{5 \mathrm{TL}}=2 \Delta \mathrm{r}_{5 \#}=2\left(\mathrm{f}_{5 \# \mathrm{c} 6.75}+\mathrm{j}_{5 \# \mathrm{c} 6.75}\right) \\
\mathrm{r}_{5 \mathrm{TL} \_c 6.75}+\Delta \mathrm{g}_{\mathrm{f}}=\mathrm{r}_{5 \mathrm{BL} \_\mathrm{c} 6.75}+\Delta \mathrm{m}_{\mathrm{f}}
\end{gathered}
$$

Solving Equation (11) once for $\Delta \mathrm{m}_{\mathrm{f}}$ and once $\Delta \mathrm{g}_{\mathrm{f}}$ results in Equations (12) and (13). With these equations, Equation (11) may further be modified to form Equation (14) by subtracting r\#_C0 from both sides. Next, by substituting Equation (8) into both sides of 
Equation (14), which in conjunction with using Equations (12) and (13) gives the resulting Equation (15).

$$
\begin{gathered}
\Delta \mathrm{m}_{\mathrm{f}}=\mathrm{r}_{5 \mathrm{TL} \_c 6.75}+\Delta \mathrm{g}_{\mathrm{f}}-\mathrm{r}_{5 \mathrm{BL} \_c 6.75} \\
\Delta \mathrm{g}_{\mathrm{f}}=\mathrm{r}_{5 \mathrm{BL} \_c 6.75}+\Delta \mathrm{m}_{\mathrm{f}}-\mathrm{r}_{5 \mathrm{TL} \_c 6.75} \\
\mathrm{r}_{5 \mathrm{TL} \_c 6.75}-\mathrm{r}_{\#_{\mathrm{c} 0}}+\Delta \mathrm{g}_{\mathrm{f}}=\mathrm{r}_{5 \mathrm{BL}} \mathrm{c} 6.75-\mathrm{r}_{\text {\#_c } 0}+\Delta \mathrm{m}_{\mathrm{f}} \\
\Delta \mathrm{r}_{5 \mathrm{TL}}+\Delta \mathrm{g}_{\mathrm{f}}=\Delta \mathrm{r}_{5 \mathrm{BL}}+\Delta \mathrm{m}_{\mathrm{f}}
\end{gathered}
$$

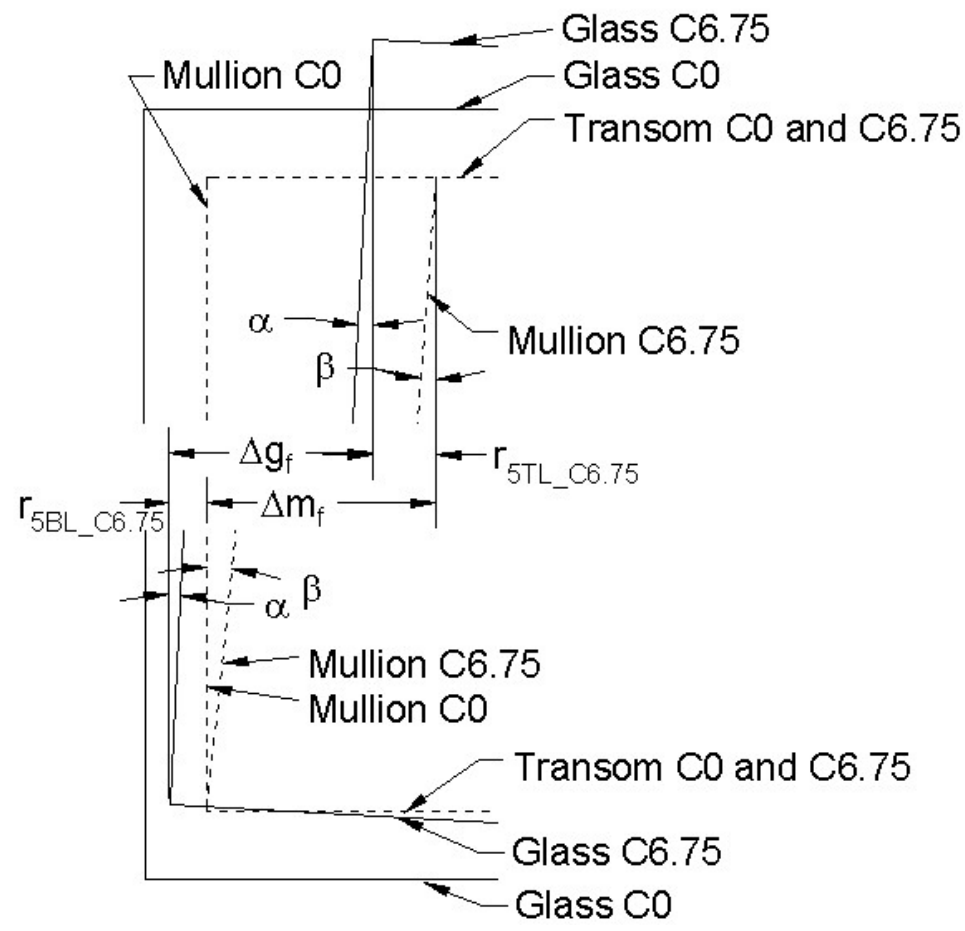

Figure 12. Top left and bottom left corner of glass pane 5 at C0 and C6.75 step 16 .

The values of $\Delta \mathrm{r}_{5 \mathrm{TL}}$ and $\Delta \mathrm{r}_{5 \mathrm{BL}}$ are assumed to be equal based on the movement of the pane in the curtain wall, but opposite in sign (based on location). This relationship gives Equations (16) and (17).

$$
\begin{gathered}
\Delta \mathrm{g}_{\mathrm{f}}=-2 \times \Delta \mathrm{r}_{5 \#}+\Delta \mathrm{m}_{\mathrm{f}} \\
\Delta \mathrm{m}_{\mathrm{f}}=2 \times \Delta \mathrm{r}_{5}+\Delta \mathrm{g}_{\mathrm{f}}
\end{gathered}
$$

From the rotation angles, the displacement/rotation shown in Figure 7 results in Equations (18) and (19). Here, Equation (19) is in reference to the left side of the glass pane while with the changing the numerator to $=-r_{5 T R_{-} c 6.75}+\Delta g_{f}+r_{5 B R_{-} c 6.75}$ will represent the right side of the glass pane.

$$
\begin{gathered}
\tan \alpha=\alpha=\frac{\Delta \mathrm{g}_{\mathrm{f}}}{\mathrm{h}_{\#}} \\
\beta_{\mathrm{m}} \cong \tan \beta_{\mathrm{m}}=\frac{\Delta \mathrm{m}_{\mathrm{f}}}{\mathrm{h}_{\#}-2 \times \mathrm{s}_{\text {\#_c } 0}}=\frac{\mathrm{r}_{5 \mathrm{TL} \_c 6.75}+\Delta \mathrm{g}_{\mathrm{f}}-\mathrm{r}_{5 \mathrm{BL} \_\mathrm{c} 6.75}}{\mathrm{~h}_{5}-2 \times \mathrm{s}_{\# \_c 0}}=\frac{2 \times \Delta \mathrm{r}_{5}+\Delta \mathrm{g}_{\mathrm{f}}}{\mathrm{h}_{5}-2 \times \mathrm{s}_{\# \_c 0}}
\end{gathered}
$$

Lastly by subtracting Equation (18) from Equation (19) then gives Equation (20).

$$
\beta_{\mathrm{m}}-\alpha=\frac{\Delta \mathrm{m}_{\mathrm{f}}}{\mathrm{h}_{\#}-2 \times \mathrm{s}_{\#-\mathrm{c} 0}}-\frac{\Delta \mathrm{g}_{\mathrm{f}}}{\mathrm{h}_{\#}}=\frac{\mathrm{r}_{5 \mathrm{TLc} 6.75}+\Delta \mathrm{g}_{\mathrm{f}}-\mathrm{r}_{5 \mathrm{BL}} \mathrm{L}_{\mathrm{c} .75}}{\mathrm{~h}_{5}-2 \times \mathrm{s}_{\#-\mathrm{c} 0}}-\frac{\Delta \mathrm{g}_{\mathrm{f}}}{\mathrm{h}_{\#}}=\frac{2 \times \Delta \mathrm{r}_{5}+\Delta \mathrm{g}_{\mathrm{f}}}{\mathrm{h}_{\#}-2 \times \mathrm{s}_{\# \mathrm{c} 0}}-\frac{\Delta \mathrm{g}_{\mathrm{f}}}{\mathrm{h}_{\#}}
$$




\subsection{Movement and Rotation Example}

Having the previously defined equations, a verification of the results was conducted. Presented here is an example to show that the relations for the angles developed based on the transom and the mullion have similar results with the created equations. Calculations in this section use equations derived based on the mockup geometry and the conditions. This example utilizes data from a 6 in. $(152.4 \mathrm{~mm})$ racking drift applied and a $c_{\text {angle }}=0.537 \mathrm{rad}$. From Equations (2) and (3), we obtain, respectively, $\beta_{\mathrm{m}}=-0.01826 \mathrm{rad}$ and $\alpha=0.00981$. The following inputs are measured values of $\alpha$ from the video analysis of MB_T2_S12_C.6.75 [25] for pane 5, respectively, at the bottom left (BL), bottom right (BR), top left (TL), and top right (TR), $0.0116 \mathrm{rad}, 0.0022 \mathrm{rad}, 0.0125 \mathrm{rad}$, and $0.0107 \mathrm{rad}$.

Though the calculated angle at the bottom right of glass pane 5 is much lower than the other locations and the theoretical value of $0.0098 \mathrm{rad}$, the average of the four locations is $0.0092 \mathrm{rad}$, which is very close to the theoretical value $(0.0098 \mathrm{rad})$. Thus, this equation is a good approximation if the average of all four corners is taken. Rotation was recorded as 0.56 degrees ( $0.0098 \mathrm{rad})$ at location $5 \mathrm{~S} 3$ and 0.82 degrees $(0.0143 \mathrm{rad})$ at location $5 \mathrm{~S} 1$. The calculated $\alpha$ value for the left side (5S3) is close to the theoretical value of $0.0098 \mathrm{rad}$. However, the right side (5S1) is $49 \%$ more than that of the theoretical value. This shows that the rotation of the glass should not be determined by just one edge value. It was found to be preferable to the average be taken from the measurements along both sides while also averaging the results from the equations based on the transom. Doing this with Equation (20) with the given mullion measurements results in: $\beta_{\mathrm{m}}=0.01216 \mathrm{rad}$ for $5 \mathrm{~S} 3$, and $0.01845 \mathrm{rad}$ for $5 \mathrm{~S} 1$.

Furthermore, the deformation of the SS along the transom is related to $\alpha$. Here, the deformation of the SS along the mullion is related to $\beta_{\mathrm{m}}-\alpha$. From Equation (20), we obtain the following values: $\beta_{\mathrm{m}}-\alpha=0.00845$ rad based on theoretical values, and 0.00502 rad according to the average of the values calculated based on video analysis.

These two values show that the differences of $\alpha$ and $\beta_{\mathrm{m}}$ from the theoretical values can lead to even larger differences in the calculated value of $\beta_{m}-\alpha$. In reviewing this difference, there is more uncertainly in strain on the mullion calculation as compared to that of the strain on the transom. However, the $\alpha$ is much greater than the $\beta_{m}-\alpha$ from both the theoretical and video analysis results [25]. Thus, the displacement of the SS along the transom will be greater than the displacement of the SS along the mullion.

\subsection{Shear Strain Limit Derivation}

The objective of the shear strain limit equation derivation was to determine if the structure silicone (SS) failure drift limit $\left(\delta_{\mathrm{S}}\right)$ occurs. A major assumption here is that there is no glass pane corner contact between adjacent panes in the curtain wall. In the larger design context, this type of behavior is a serviceability limit as compared to an ultimate limit state and thus not as critical. In cases of this behavior when the SS fails first, there is not an immediate life-safety occupant threat. The only issue is that there potentially is a repair cost to re-glaze the glass panes in situ (if the glazing is damaged). Once the shear strain limit is reached in the curtain wall, the occupant life-safety becomes a major concern as at higher drifts, the SS failure can propagate to the entire glass pane perimeter, which can lead to the entire glass pane possibly falling out or shattering the glazing if it is fully tempered.

Utilizing the relations described in the previous Sections 3.1 and 3.2 for the relative glass pane corner movement of the frame will now be related to when the SS reaches its ultimate shear elongation. As part of this derivation, the relations will be made to the overall drift $\left(\delta_{\mathrm{s}}\right)$ of the mockup at the supports (Equation (9)). Once $\delta_{\mathrm{s}}$ is reached, the drift ratio $\left(\delta_{\mathrm{s}} / \mathrm{H}_{\mathrm{s}}=\delta / \mathrm{H}\right)$ and the drift $(\delta)$ over the entire height of the mockup may be calculated using Equation (9). With a combined longitudinal shear and transverse shear, there are two methods we can utilize defined by Method 1 (Equation (21)) and Method 2 (Equation (22)). $\Delta \mathrm{r}_{\#}$ is the longitudinal shear displacement of the SS along the transom (Equation (8)), and $\Delta s_{\#}$ is the transverse shear displacement of the SS along the transom (Equation (7)). $\Delta t_{\#}$ is 
the effective shear displacement of a SS and is equal to the multiplication of the thickness $(X)$ and the ultimate shear elongation $(\gamma)$ as shown in Equation (23).

$$
\begin{aligned}
\text { forMethod1 } \Delta \mathrm{t}_{\#} & =\left|\Delta \mathrm{r}_{\#}\right|+\left|\Delta \mathrm{s}_{\#}\right| \\
\text { forMethod2 } \Delta \mathrm{t}_{\#} & =\sqrt{\Delta \mathrm{r}_{\#}^{2}+\Delta \mathrm{s}_{\#}^{2}} \\
\Delta t_{\#} & =X \gamma
\end{aligned}
$$

Substituting Equations (21) and (22) into Equation (23) gives Equation (24) for Method 1 and Equation (25) for Method 2.

$$
\begin{gathered}
\text { forMethod1 } \mathrm{X} \gamma=\left|\Delta \mathrm{r}_{\#}\right|+\left|\Delta \mathrm{s}_{\#}\right| \\
\text { forMethod2 } \mathrm{x} \gamma=\sqrt{\Delta \mathrm{r}_{\#}^{2}+\Delta \mathrm{s}_{\#}^{2}}
\end{gathered}
$$

From here, the movement of the glass relative to the frame $\left(\Delta \mathrm{r}_{\#}\right.$ and $\left.\Delta \mathrm{s}_{\#}\right)$ are related to each other. $\Delta \mathrm{s}_{\#}$ can now be solved for and substituted into the drift ( $\delta$ ) (Equation (9)). The relationship between $\Delta \mathrm{s}_{\#}$ and $\alpha$ (Equation (5)) is similar to the relationship between $\Delta \mathrm{r}_{\#}$ and $\alpha$, which leads to Equation (26), from which we can solve for $\Delta \mathrm{r}_{\#}$ given in Equation (27).

$$
\begin{aligned}
2 \frac{\Delta_{\mathrm{S} \#}}{\mathrm{w}_{5}}=\alpha=2 \frac{\Delta_{\mathrm{r} \#}}{\mathrm{~h}_{5}} \\
\Delta_{\mathrm{r} \#}=\mathrm{h}_{5} \frac{\Delta_{\mathrm{S} \#}}{\mathrm{w}_{5}}
\end{aligned}
$$

Performing these substitutions, the variables $\Delta \mathrm{r}_{\#}$ and $\Delta \mathrm{s}_{\#}$ are now in a relationship to each other and by using Equation (27) by substituting into Equations (24) and (25). Starting with the first method, substituting Equation (27) into Equation (24) gives Equation (28), which is the relationship of the ultimate shear strain limit to the vertical movements of the glass pane corner relative to the frame.

$$
\mathrm{x}_{\gamma}=\left|\Delta \mathrm{r}_{\#}\right|+\left|\Delta \mathrm{s}_{\#}\right|=\left|\mathrm{h}_{5} \frac{\Delta_{\mathrm{S \#}}}{\mathrm{w}_{5}}\right|+\left|\Delta \mathrm{s}_{\#}\right|=\left|\Delta \mathrm{s}_{\#}\right|\left(\frac{\mathrm{h}_{5}}{\mathrm{w}_{5}}+1\right)
$$

Solving for $\Delta s_{\#}$ then gives Equation (29), which is then substituted into Equation (9) to form Equation (30).

$$
\begin{gathered}
\left|\Delta \mathrm{s}_{\#}\right|=\frac{\mathrm{X} \gamma}{\left(\frac{\mathrm{h}_{5}}{\mathrm{w}_{5}}+1\right)} \\
\delta_{\mathrm{s}, 1 \text { st method }}=2 \frac{\Delta_{\mathrm{S} 5 \#}}{\mathrm{w}_{5}}\left(\frac{\mathrm{H}_{\mathrm{S}}}{\mathrm{c}_{\text {angle }}}\right)=\frac{2}{\mathrm{w}_{5}}\left(\frac{\mathrm{X} \gamma}{\left(\frac{\mathrm{h}_{5}}{\mathrm{w}_{5}}+1\right)}\right)\left(\frac{\mathrm{H}_{\mathrm{S}}}{\mathrm{c}_{\text {angle }}}\right)=2 \frac{\mathrm{X} \gamma}{\mathrm{h}_{5}+\mathrm{w}_{5}}\left(\frac{\mathrm{H}_{\mathrm{S}}}{\mathrm{c}_{\text {angle }}}\right)
\end{gathered}
$$

Finally, Equation (30) is solved for the effective shear strain $(\gamma)$ as calculated by Method 1. Equation (31) is useful for determining the shear strain of the SS for any drift.

$$
\gamma_{\mathrm{s}, 1 \mathrm{st} \text { method }}=0.5 \delta_{\mathrm{s}} \frac{\mathrm{h}_{5}+\mathrm{w}_{5}}{\mathrm{X}}\left(\frac{\mathrm{c}_{\text {angle }}}{\mathrm{H}_{\mathrm{S}}}\right)
$$

Next, the equation for $\Delta s_{\#}$ was derived using Method 2. This process is the same as Method 1, except the algebraic relationship was more complicated due to the quadratic equation form in the equation. Here, Equation (27) is substituted into Equation (25), which gives Equation (32).

$$
\mathrm{X} \gamma=\sqrt{\Delta \mathrm{r}_{\#}{ }^{2}+\Delta \mathrm{s} \#_{\#}^{2}}=\sqrt{\left(\mathrm{h}_{5} \frac{\Delta_{\mathrm{S} \#}}{\mathrm{w}_{5}}\right)^{2}+\Delta \mathrm{s}_{\#}{ }^{2}}=\Delta \mathrm{s}_{\#} \sqrt{\left(\frac{\mathrm{h}_{5}}{\mathrm{w}_{5}}\right)^{2}+1}
$$


Solving for $\Delta s_{\#}$ then gives Equation (33), which is then substituted into Equation (9) to form Equation (34).

$$
\delta_{\mathrm{s}, 2 \text { nd method }}=2 \frac{\Delta_{\mathrm{S} 5 \#}}{\mathrm{w}_{5}}\left(\frac{\mathrm{H}_{\mathrm{S}}}{\mathrm{c}_{\text {angle }}}\right)=\frac{2}{\mathrm{w}_{5}}\left(\frac{\mathrm{X} \gamma}{\sqrt{\left(\frac{\mathrm{h}_{5}}{\mathrm{w}_{5}}\right)^{2}+1}}\right)\left(\frac{\mathrm{H}_{\mathrm{S}}}{\mathrm{c}_{\text {angle }}}\right)=2 \frac{\mathrm{X} \gamma}{\sqrt{\mathrm{h}_{5^{2}+\mathrm{w}_{5}^{2}}}}\left(\frac{\mathrm{H}_{\mathrm{S}}}{\mathrm{c}_{\text {angle }}}\right)
$$

Equation (34) can now be solved for $\gamma$, which represents the effective shear strain calculated by Method 2. Equation (35) can be used to determine the shear strain of the SS for any drift.

$$
\gamma_{\mathrm{s}, 2 \text { nd method }}=0.5 \delta_{\mathrm{s}} \frac{\sqrt{\mathrm{h}_{5}^{2}+\mathrm{w}_{5}^{2}}}{\mathrm{X}}\left(\frac{\mathrm{c}_{\text {angle }}}{\mathrm{H}_{\mathrm{S}}}\right)
$$

\subsection{Validation of Equation to Estimate SS}

While Equations (30) and (34) can be applied to any glass pane making up panels 1, 2,3 , row 2 of glass panes (P4, P5, and P6), seems to be more critical compared to glass pane rows 1 and 3 . The reason is that row 2 had the largest rotation and largest amount of $c_{\text {angle }}$ of 0.537 during physical testing. Substituting the dimensions and properties of the SS into Equations (31) and (34), it yields the following values, noting that the utilized properties are $X=5 / 16$ in. $(7.94 \mathrm{~mm}), \gamma=2$ (a 200\% ultimate shear strain; and the mockup dimensions $\left(\mathrm{H}_{\mathrm{s}}=9.33 \mathrm{ft}\right.$. $(2844 \mathrm{~mm}), \mathrm{w}_{5}=4.5 \mathrm{ft}$. $(1372 \mathrm{~mm})$, and $\mathrm{h}_{5}=6 \mathrm{ft}$. $\left.(1829 \mathrm{~mm})\right)$ : $\delta_{\mathrm{s}, 1 \mathrm{st} \text { method }}=2.07 \mathrm{in}$. and $\delta_{\mathrm{s}, 2 \text { nd method }}=2.90 \mathrm{in}$.

The SS failure for physical mockup MB_T2 was first observed to occur at Step 16. At this point, the combined upper and lower tube displacement was $2.50 \mathrm{in}$. $(63.5 \mathrm{~mm})$ at C6.25 and 2.55 in $(64.8 \mathrm{~mm})$ at C6.75 for Step 15 and was 2.67 in $(67.8 \mathrm{~mm})$ at C6.25 and 2.73 in $(69.3 \mathrm{~mm})$ at $\mathrm{C} 6.75$ for Step 16 . This failure occurred most probably when the upper and lower tube displacement reached a drift range of $2.55 \mathrm{in}(64.8 \mathrm{~mm})$ to $2.73 \mathrm{in}(69.3 \mathrm{~mm})$, with an average of $2.64 \mathrm{in}$. $(67.0 \mathrm{~mm})$. This average is $28 \%$ larger than $2.07 \mathrm{in}$. $(52.6 \mathrm{~mm})$ predicted by Method 1, but $9 \%$ less than 2.90 in. $(73.7 \mathrm{~mm}$ ) when predicted by Method 2. A possibility for the differences is that a lower drift could have initiated the failure, but it was not detected during testing inspection until Step 16. A second possible difference stems from the sum of the upper and lower tube displacements that were actually larger than the drift imposed on the mockup due to connection angle flexibility. Neither Equations (30) nor (34) takes these two factors into account as it was an added complexity that had too many variables and uncertainty in how all curtain walls are attached.

Potential drift over-prediction could also have come from any SS bead imperfections or any glass translations. Likely a SS bead imperfection would lead to failure before the $200 \%$ ultimate shear strain recorded from the coupon testing. Derived Equations (30) and (34) rely only on rotation and ignore translation. Any glass pane translation would cause additional SS shear strain, which may lead to premature SS failure. Method 1 calculated a drift of 2.07 in $(52.6 \mathrm{~mm})$ can be considered conservative for SS failure prediction. On the other hand, Method 2 calculated a drift of 2.90 in $(73.7 \mathrm{~mm})$ can then be considered an over-predicted drift limit. Nonetheless, the results of this example show that using the kinematic equations derived can lead to reasonable estimates of drift capacity prediction.

\subsection{Limit State Derivation—Drift Ratio Causing Glass-to-Glass Corner Contact Prior to SS Failure}

This section covers the typical movement behavior of the glass corners relative to the frame. Figure 13a,b represent the adopted nomenclature for a glass pane rotating when isolated from the frame. Here, $w_{n}$ is the width of glass pane $n ; h_{n}$ is the height of glass 
pane $n ; f_{n}$ is the horizontal movement of glass pane $n$ at each corner due to rotation $\left(\alpha_{n}\right)$; and lastly, $\mathrm{e}_{\mathrm{n}}$ is the vertical movement of glass pane $\mathrm{n}$ at each corner due to rotation $\left(\alpha_{n}\right)$.

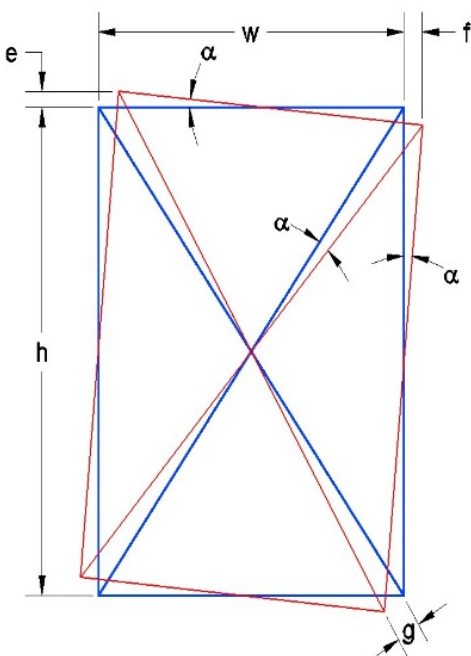

(a)

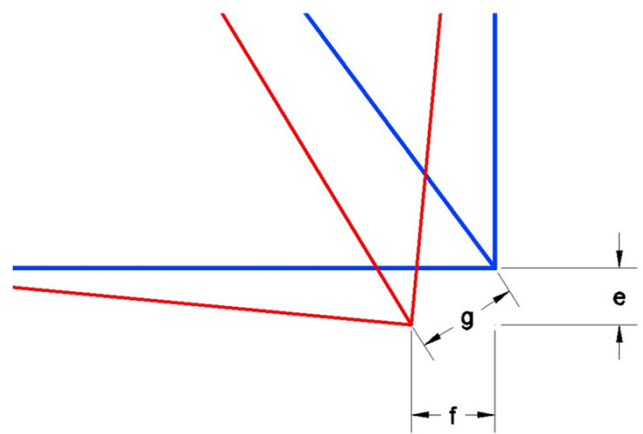

(b)

Figure 13. Close-up of exaggerated geometric rotation of a glass pane about its center. (a) Full panel geometric rotation; (b) corner exaggerated geometry.

The relationships between these parameters are as follows in Equations (36) and (37).

$$
\begin{aligned}
& \mathrm{e}=\frac{\alpha \mathrm{w}}{2} \\
& \mathrm{f}=\frac{\alpha \mathrm{h}}{2}
\end{aligned}
$$

A limit state of interest to this research study is contact between glass panes represented by the drift $\left(\delta_{\mathrm{s}}\right)$ when the gap closed, which represents a serviceability limit state of the curtain wall. Initial contact between glass panes is not an immediate life-safety threat as the panel has not been damaged yet. However, this will start some corner crushing and/or cracking of the glass pane with significant repair costs. The life-safety limit state occurs at higher drifts when a piece of glass $\left(1 \mathrm{in.}^{2}\left(645.2 \mathrm{~mm}^{2}\right)\right.$ area or larger) falls from the mockup. This condition is defined as an ultimate limit state according to AAMA 501.6. At this limit state, some nonlinearity can be observed at which point the FEM analysis and the kinematic equation for SS failure become invalid. The objective of the equation that is derived herein determines the drift $\left(\delta_{\mathrm{s}}\right)$ of the mockup at which a glass pane corner or side contacts another glass pane corner or side.

For this derivation, it was assumed that the SS will not fail. Initially, movement of one pane's corner relative to the corner of another pane will be derived. Figure 14 shows the exaggerated deformed shape to illustrate the geometry at the instant that glass pane 5 contacts glass pane 3 . In Figure $14, w_{m}$ is the width of the mullion; $w_{t}$ is the width of the transom; $j_{n}$ is the horizontal movement of glass pane $n$ relative to its center due to translation; $k_{n}$ is the vertical movement of glass pane $n$ relative to its center due to translation; $\mathrm{f}_{\mathrm{n}}$ is the horizontal movement of glass pane $\mathrm{n}$ at each corner due to rotation $\left(\alpha_{n}\right)$; and $e_{n}$ is the vertical movement of glass pane $n$ at each corner due to rotation, $\alpha_{n}$. Contact will only occur when both Equations (38) and (39) are true.

$$
\begin{aligned}
& \text { Mullion weather }- \text { seal width }=\mathrm{w}_{\mathrm{m}} \leq\left(\mathrm{f}_{5}+\mathrm{j}_{5}\right)-\left(\mathrm{f}_{3}+\mathrm{j}_{3}\right)\{\text { right is positive }\} \\
& \text { Transom weather }- \text { seal width }=\mathrm{w}_{\mathrm{t}} \leq\left(\mathrm{e}_{3}+\mathrm{k}_{3}\right)-\left(\mathrm{e}_{5}+\mathrm{k}_{5}\right) \quad\{\text { up is positive }\}
\end{aligned}
$$




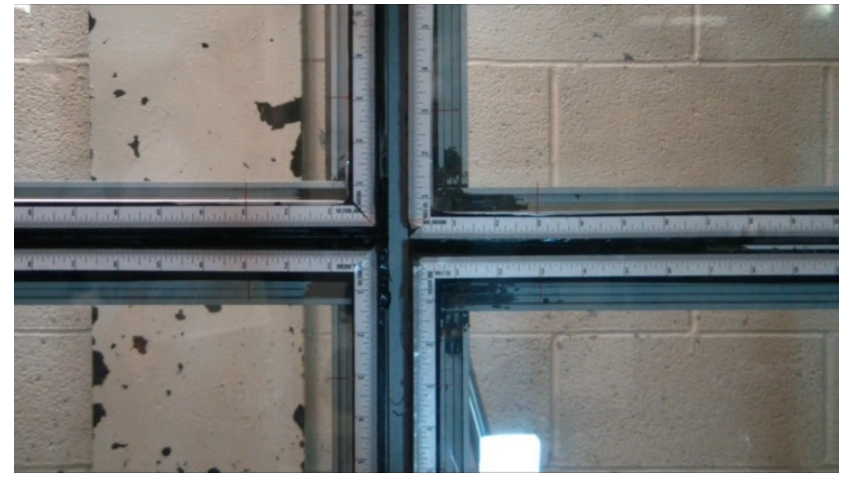

(a)

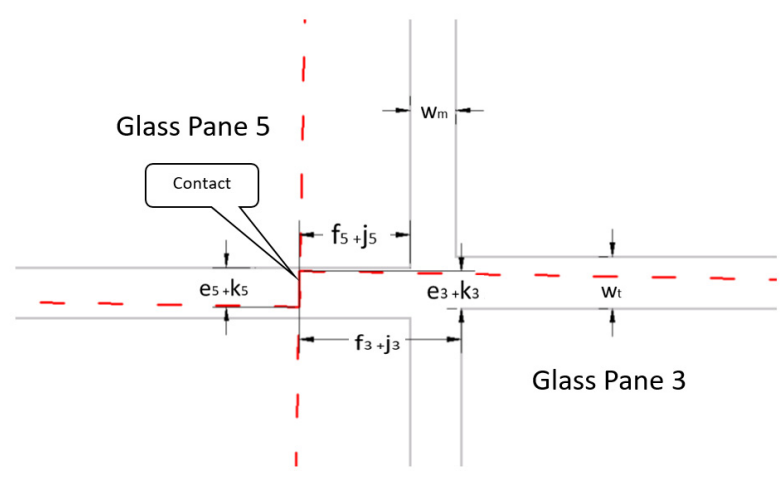

(b)

Figure 14. Glass panes 3 and 5 movement. (a) Relative glass pane positions at one instant of time during racking; (b) movement of glass panes 3 and 5 at contact relative to the undeformed positions of the glass panes.

The weather-seal widths are given from the curtain wall design. From the example given (Figure 10$), \mathrm{w}_{\mathrm{m}}$ is $0.45 \mathrm{in}$. $(11.43 \mathrm{~mm})$ and $\mathrm{w}_{\mathrm{t}}$ is $0.51 \mathrm{in} .(12.95 \mathrm{~mm})$. The measurements from the video analysis of specific example at a lower drift in which contact has not yet occurred were $\left(f_{5}+j_{5}\right)=-1.20$ in. $(30.48 \mathrm{~mm}) ;\left(f_{3}+j_{3}\right)=-1.48$ in. $(37.59 \mathrm{~mm})$; $\left(\mathrm{e}_{5}+\mathrm{k}_{5}\right)=-0.39$ in. $(9.91 \mathrm{~mm}) ;\left(\mathrm{e}_{3}+\mathrm{k}_{3}\right)=0.36$ in. $(9.14 \mathrm{~mm})$. Substituting these values into Equations (39) and (40) leads to the following values and comparisons:

$$
\begin{gathered}
\mathrm{w}_{\mathrm{m}}=0.45 \mathrm{in} . \leq(-1.20 \mathrm{in} .)-(-1.48 \text { in. })=0.28 \mathrm{in.} \text { false } \\
\mathrm{w}_{\mathrm{t}}=0.51 \mathrm{in} . \leq 0.36 \mathrm{in} .-(-0.39 \mathrm{in} .)=0.75 \mathrm{in} . \text { true }
\end{gathered}
$$

Since both statements are not true, this implies that contact has not occurred, which is in fact the case for this drift. The following derivation steps are required, because of the need to predict the displaced (translation and rotation) shape of the glass panes relative to each other.

The two conditions necessary for contact to occur (Equations (38) and (39)) were developed separately (so that they may be estimated in Equation (2)) to form two separate final equations (Equations (47) and (51)) predicting $\delta_{\mathrm{s}}$, glass-glass contact. Only one of the final equations will control for any given mockup geometry. First, the condition of Equation (39) was developed, which determined the drift at which the glass panes have closed the horizontal gap between them. Equations (40)-(42) were developed based on the geometry of Figure 4 and assuming that the horizontal translation of the glass pane, $j_{n}$, is the same as that of the mullions:

$$
\begin{gathered}
\mathrm{j}_{\mathrm{n}}=\overline{\mathrm{Y}}_{\mathrm{n}} \beta_{\mathrm{m}} \\
\mathrm{j}_{3}=\overline{\mathrm{Y}}_{3} \beta_{\mathrm{m}}=\frac{\mathrm{h}_{3}}{2} \beta_{\mathrm{m}} \\
\mathrm{j}_{5}=\overline{\mathrm{Y}}_{5} \beta_{\mathrm{m}}=\left(\mathrm{h}_{3}+\frac{\mathrm{h}_{5}}{2}\right) \beta_{\mathrm{m}}
\end{gathered}
$$

Substituting Equations (38), (41) and (42) into Equation (39) resulted in Equation (43), which simplifies to Equation (44). $f_{n}$ is the horizontal movement of the glass pane $n$ at each corner due to rotation.

$$
\begin{aligned}
& \mathrm{w}_{\mathrm{m}} \leq\left(\mathrm{f}_{5}+\mathrm{j}_{5}\right)-\left(\mathrm{f}_{3}+\mathrm{j}_{3}\right)=\left(-\frac{\alpha \mathrm{h}_{5}}{2}+\left(\mathrm{h}_{3}+\frac{\mathrm{h}_{5}}{2}\right) \beta_{\mathrm{m}}\right)-\left(\frac{\alpha \mathrm{h}_{3}}{2}+\frac{\mathrm{h}_{3}}{2} \beta_{\mathrm{m}}\right) \\
& \mathrm{w}_{\mathrm{m}} \leq \alpha\left(-\frac{\mathrm{h}_{5}}{2}-\frac{\mathrm{h}_{3}}{2}\right)+\beta_{\mathrm{m}}\left(\mathrm{h}_{3}+\frac{\mathrm{h}_{5}}{2}-\frac{\mathrm{h}_{3}}{2}\right)=-\frac{\alpha}{2}\left(\mathrm{~h}_{5}+\mathrm{h}_{3}\right)+\frac{\beta_{\mathrm{m}}}{2}\left(\mathrm{~h}_{3}+\mathrm{h}_{5}\right)
\end{aligned}
$$


Next, substituting Equation (3) into Equation (44) would allow the derivation to continue with Equations (44) and (46). Substituting Equation (46) into Equation (2) then gives Equation (47).

$$
\begin{gathered}
\mathrm{w}_{\mathrm{m}} \leq-\frac{\mathrm{c}_{\text {angle }} \beta_{\mathrm{m}}}{2}\left(\mathrm{~h}_{5}+\mathrm{h}_{3}\right)+\frac{\beta_{\mathrm{m}}}{2}\left(\mathrm{~h}_{3}+\mathrm{h}_{5}\right)=\frac{\beta_{\mathrm{m}}}{2}\left(\mathrm{~h}_{3}+\mathrm{h}_{5}\right)\left(1-\mathrm{c}_{\text {angle }}\right) \\
\beta_{\mathrm{m}} \geq \frac{2 \mathrm{w}_{\mathrm{m}}}{\left(\mathrm{h}_{5}+\mathrm{h}_{3}\right)\left(1-\mathrm{c}_{\text {angle }}\right)} \\
\delta_{\mathrm{s}_{\text {- horizontal gap closes }}} \geq \frac{2 \mathrm{w}_{\mathrm{m}}}{\left(\mathrm{h}_{5}+\mathrm{h}_{3}\right)\left(1-\mathrm{c}_{\text {angle }}\right)} \mathrm{H}_{\mathrm{s}}
\end{gathered}
$$

Next, the condition of Equation (39) was developed. This determined the drift at which the glass panes have closed the vertical gap between them. Observation of the physical testing and video capture analysis indicated that the vertical movement of glass panes, $\mathrm{k}_{\mathrm{n}}$, was minimal (e.g., measurements from video capture were $\mathrm{j}_{5}=0.3406 \mathrm{in}$. $(8.6512 \mathrm{~mm})$; $\mathrm{k}_{5}=0.0192$ in. $(0.4877 \mathrm{~mm}) ; j_{3}=2.0189$ in. $(51.2801 \mathrm{~mm}) ;$ and $\mathrm{k}_{3}=0.0192$ in. $(0.4877 \mathrm{~mm})$ ). The value of $k_{n}$ is assumed zero for simplicity of the following derivations. Substituting Equation (37) and $k_{n}=0$ into Equation (40) gives Equations (48)-(50).

$$
\begin{gathered}
\mathrm{w}_{\mathrm{t}} \leq\left(\mathrm{e}_{3}+\mathrm{k}_{3}\right)-\left(\mathrm{e}_{5}+\mathrm{k}_{5}\right)=\left(\frac{\alpha \mathrm{w}_{3}}{2}+0\right)-\left(-\frac{\alpha \mathrm{w}_{5}}{2}+0\right)=\left(\alpha \mathrm{w}_{3}+\alpha \mathrm{w}_{5}\right) \\
\mathrm{w}_{\mathrm{t}} \leq \alpha\left(\mathrm{w}_{3}+\mathrm{w}_{5}\right)=\mathrm{c}_{\text {angle }} \beta\left(\mathrm{w}_{3}+\mathrm{w}_{5}\right) \\
\beta \geq \frac{\mathrm{w}_{\mathrm{t}}}{\mathrm{c}_{\text {angle }}\left(\mathrm{w}_{3}+\mathrm{w}_{5}\right)}
\end{gathered}
$$

Substituting Equation (50) into Equation (2) resulted in Equation (51):

$$
\delta_{\mathrm{s}_{-} \text {vertical gap closes }} \geq \frac{\mathrm{w}_{\mathrm{t}}}{\mathrm{c}_{\text {angle }}\left(\mathrm{w}_{3}+\mathrm{w}_{5}\right)} \mathrm{H}
$$

Equations (47) and (51) determine the gap_closed drift $\left(\delta_{\mathrm{s}}\right.$, defined as the condition at which both the horizontal and vertical gaps close. In these equations, $\mathrm{w}_{\mathrm{m}}=$ width of the weather-seal along the mullion (i.e., the horizontal glass pane gap s); $w_{t}=$ weatherseal width along the transom (i.e., the vertical glass pane gap); $\mathrm{h}_{\mathrm{n}}=$ glass pane height; $\mathrm{w}_{\mathrm{n}}=$ glass pane width; $\mathrm{H}_{\mathrm{s}}=$ inter-story mockup height between the boundary connection points (the tubes in the facility); and $\mathrm{c}_{\mathrm{angle}}=$ glass pane rotation coefficient. Predicting the glass pane movement with respect to the frame becomes increasingly more complicated once either limit states are exceeded. For any given mockup, either the failure of the SS or glass contact limits will control.

\subsection{Drift Equation Example}

Substitution of the dimensions of the mockup that are $\mathrm{H}_{\mathrm{s}}=9.33 \mathrm{ft}(2843 \mathrm{~mm}), \mathrm{w}_{\mathrm{m}}=\frac{3}{4}$ " $(19 \mathrm{~mm}), \mathrm{w}_{\mathrm{t}}=\frac{1}{2}{ }^{\prime \prime}(12.7 \mathrm{~mm}), \mathrm{w}_{3}=4.5 \mathrm{ft} .(1372 \mathrm{~mm})$, and $\mathrm{w}_{5}=4.5 \mathrm{ft} .(1372 \mathrm{~mm}), \mathrm{h}_{3}=2.5 \mathrm{ft}$. $(762 \mathrm{~mm})$, and $\mathrm{h}_{5}=6 \mathrm{ft}$. $(1829 \mathrm{~mm})$ into Equation (47) and Equation (51) and using the assumed value of $\mathrm{c}_{\text {angle }}=0.537$ yields:

$$
\begin{aligned}
\delta_{\mathrm{s}_{,- \text {horizontal gap closes }}} & =\frac{2 \times 0.75 \mathrm{in} .}{(2.5 \mathrm{ft} .+6 \mathrm{ft})(1-0.537)} 9.33 \mathrm{ft} .=3.56 \mathrm{in} . \\
\delta_{\mathrm{s}_{- \text {vertical gap closes }}} & =\frac{0.5 \mathrm{in} .}{0.573(4.5 \mathrm{ft} .+4.5 \mathrm{ft})} 9.33 \mathrm{ft} .=0.97 \mathrm{in} .
\end{aligned}
$$

As mentioned previously, both Equations (38) and (39) must be true in order for contact to occur. Thus, contact inter-story drift is the larger of values determined from Equations (47) and (51). Assuming that $\mathrm{c}_{\text {angle }}$ is $0.573 \mathrm{rad}$ and the test mockup dimensions 
for the research specimens, the controlling value is $3.56 \mathrm{in}$. (90.42 mm). Based on the test measurements, the combined tubes displacements (upper and lower) was $3.46 \mathrm{in}$. $(87.88 \mathrm{~mm})$ at C6.25 and $3.50 \mathrm{in} .(88.9 \mathrm{~mm})$ at C6.75 for Step 20 and was $3.89 \mathrm{in}$. (98.8 $\mathrm{mm})$ at C6.25 and 3.80 in. (95.6 mm) at C6.75 for Step 21. Accordingly, Equation (47) predicted a drift value of $3.56 \mathrm{in}$. (90.42 mm) implies that glass contact will occur during Step 21, which was confirmed from observations of MB_T2_S12 test results. In summary, glass pane 6 suddenly changed in behavior at S21_C3.75 and at S21_C4.25 the lower-left side of glass pane 6 made contact with the bottom-right side of glass pane 5. Accordingly, Equations (47) and (51) can acceptably predict curtain wall drift at the glass-glass contact, even though some failure of SS was observed at Step 16 (at $\left.\delta_{\mathrm{S}}=2.64 \mathrm{in} .(67.06 \mathrm{~mm})\right)$, and that there were major SS failures at Step 21 just before the onset of glass contact. Based on test observations, if the failure of the SS had not occurred prior to glass contact, then a larger magnitude glass contact drift may have resulted. In such a situation, the resulting prediction estimates from Equations (47) and (51) would have underestimated the drift capacity, resulting in a more conservative design.

\section{Discussion}

From the resulting derivations that generated both Equations (30) and (34), these two equations can be adopted by designers for predicting the limit state of any of the nine glass panes across Panels 1, 2, and 3. That said, the glass panes P4, P5, and P6 in Row 2 controlled the entire mockup system as compared to panes in both Rows 1 and 3 . A reason that Row 2 did control is due to Row 2 experiencing the greatest measured of glass rotation and highest coefficient $c_{\text {angle }}$ of 0.537 rad. Now looking at Equations (47) and (51), both of these equations were streamlined by only using a $c_{\text {angle }}$ equal to 0.537 rad. While an approximation, the accuracy of the Equations (47) and (51) can be improved (if desired) by re deriving them using the $c_{\text {angle }}$ coefficient from both the second row and either the first or third row (whichever other row will control first).

This paper derived equations that can predict structural sealant (SS) limit state failure occurring at a corresponding drift $\delta_{\mathrm{s}, \mathrm{ss}}$ of $2.07 \mathrm{in}$. $(52.58 \mathrm{~mm})$ using Methods 1 or $2.90 \mathrm{in}$. $(73.66 \mathrm{~mm})$ using Method 2. The actual observed drift was $2.64 \mathrm{in}$. $(67.06 \mathrm{~mm})$ from testing. Moreover, the kinematic equations predicted glass-to-glass contact at a drift $\left(\delta_{\mathrm{s}}\right.$, gap_closed) of $3.46 \mathrm{in}$. (87.88 $\mathrm{mm}$ ) compared to the actual recorded drift having a range between 3.50 in. $(88.9 \mathrm{~mm})$ to $3.89 \mathrm{in} .(98.8 \mathrm{~mm})$. The calculated effective shear strains from the kinematic-based equations are relatively close to that of the FEM [23].

The FEM model analysis results were compared to the racking test results to assess validation over the linear elastic range of structural sealant performance. The stiffness recorded from the physical testing at lower steps was similar to the FEM results while at higher steps the physical mockup showed non-linear behavior, yet the FEM was not developed with that level of non-linear behavior established in its materials or elements. Regarding the glass pane corner movement relative to the aluminum frame, resulted in considerably different values between the FEM and the physical mockups. Other observed results showed that the FEM was not significantly influenced by the perpendicular panel and that the structural silicone could be modeled with thick shell area elements in commercial software will give a good correlation experimental testing. More detailed comparisons between FEM results and physical testing results can be found in Simmons and Memari [23].

The kinematic equations have been validated by noting SS failure for MB_T2, which occurred at Step 16. The combined tubes displacements were $2.50 \mathrm{in}$. (63.5 mm) at C6.25 and $2.554 \mathrm{in.}(64.8 \mathrm{~mm})$ at C6.75 for Step 15 and was $2.67 \mathrm{in.}(67.8 \mathrm{~mm})$ at C6.25 and 2.73 in. (69.3 mm) at C6.75 for Step 16. Therefore, the failure most likely occurred when the combined tubes displacement reached a drift between $2.55 \mathrm{in}$. (64.8 $\mathrm{mm})$ and $2.73 \mathrm{in}$. $(69.3 \mathrm{~mm})$. The average of that range is $2.64 \mathrm{in}$. $(67.06 \mathrm{~mm})$, which is $28 \%$ more than the predicted value of $2.07 \mathrm{in}$. (52.58 $\mathrm{mm}$ ) from method 1 and $9 \%$ less than the predicted value of $2.90 \mathrm{in}$. (73.66 mm) from Method 2. The derivation of the first limit state determined that 
the rotation and subsequently the SS shear deformation was larger along the transom than the mullion. In other words, the shear failure of the SS is most likely to occur along the transom than the mullion, because the thickness is smaller (5/16 in. vs. 9/16 in. (7.94 mm vs. $14.29 \mathrm{~mm}))$ and the displacements are higher $\left(\beta_{\mathrm{m}}-\alpha<\alpha\right)$. The thickness of the SS along the transom should be at least equal to or more than the thickness of the SS along the mullions.

The calculated effective shear strain was relatively similar to the FEM and the kinematic equations, but not for the video analysis. The possible sources of human error from the video capture technique may be a cause of this difference.

\section{Conclusions}

The objective of this research was to develop prediction equations for four-sided structural silicone glazing (4SSG) curtain wall performance under seismic loading conditions. A series of kinematic-based equations were developed for two limit states corresponding to a pure-racking boundary condition. The first equation set predicts the $\operatorname{drift}\left(\delta_{\mathrm{s}}\right)$ that causes the onset of the SS shear strain failure based on the maximum permitted effective shear strain of $200 \%$ The second equation set predicts the glass to glass contact drift $\left(d_{s}\right)$. Both of these equation sets provide reasonable predictions for pure-racking boundary condition installed curtain wall system deploying 4SSG. The results of this study show that:

- Method 1 and 2's kinematic equations both calculate the effective shear strain limit reasonably well and are supported by applied stick-built 4SSG mockup testing at Step 16 in the testing protocol when SS failure was first observed. The equation predicted that SS failure would start at a lower drift level related to Method 1's formulation while Method 2 starts failure at a slightly larger drift.

- $\quad$ Both methods predicted effective strains to be less than the ultimate shear stain. This under-prediction by both methods was assumed to be attributed to a defect in the SS bead at the location of the failure, because another corner had a slightly higher calculated effective shear strain and did not fail.

- Glass-to-glass contact for the stick-built mockup was predicted by the derived equation when comparing results to physical testing at Step 21. Further video analysis observations though suggest that glass-to-glass contact would have occurred at a higher drift had the SS failure had not occurred at Step 16 giving way to conservative equations.

- Relative glass pane movement with respect to the frame becomes complex after either of the two limit states are reached. Based on the configurations studied, either glassto-glass contact or SS failure limit will control the overall design, and beyond that, the accuracy of the other equation diminishes.

- $\quad$ Between the mullion and the transom SS, the one with smaller thickness will first fail in shear and control the drift capacity.

Given the kinematic equations derived, each limit state from the calculations can be assumed to lead to smaller drift capacity predictions resulting in conservative estimations. These conservative estimates stem from the two primary simplifications: (1) glass panes act as a rigid body with only rotation and translation (no deformation) and (2) curtain wall mullions rotate without considerable deformations. Actual physical mockup testing has shown that curtain walls are more flexible than those assumed for kinematic relation derivation. As a result, real curtain walls will yield larger drift capacities before SS failure occurs. Another limitation imposed in this research is the assumption that other possible conditions have not or will not occur before SS failure. Another major assumption is that only linear elastic behavior is assumed, and any nonlinearity is not considered, i.e., the equations do not apply to conditions under plastic deformation or cyclic loading. Furthermore, this paper's kinematic equations are only applicable for the stick-built boundary condition.

For future studies, the rotation coefficients of the glass panes should be characterized with an equation based on the type and location of the boundary system. This would expand the utility of the kinematic equations developed in this research. The kinematic 
equation that determines when glass contact occurs should be revised to consider the difference of rotations from one row of glass panes to the next. It may be worthwhile to develop a set of kinematic-based equations for the rack with vertical-slip boundary conditions. This can be accomplished based on the derivation presented but changing some of the assumptions such as the rotation of transoms.

Author Contributions: Conceptualization, A.M.M.; methodology, A.M.M. and N.S.; software, N.S.; validation, N.S.; formal analysis, N.S.; investigation, N.S.; writing-original draft preparation, A.M.M. and R.L.S.; writing-review and editing, A.M.M. and R.L.S.; visualization, R.L.S. and N.S.; supervision, A.M.M.; project administration, A.M.M.; funding acquisition, A.M.M. All authors have read and agreed to the published version of the manuscript.

Funding: This research was partially funded by Dow and Bagatelos for supplying the materials and financial resources necessary to conduct these tests. The results of the study presented here are those of the authors and do not necessarily reflect those of the sponsors.

Institutional Review Board Statement: Not applicable.

Informed Consent Statement: Not applicable.

Data Availability Statement: Data can be found in the references provided, mainly publication under the name Memari, A. M.

Conflicts of Interest: The authors declare no conflict of interest.

\section{References}

1. American Architectural Manufacturers Association (AAMA). Recommended Dynamic Test Method for Determining the Seismic Drift Causing Glass Fallout from a Wall System; AAMA: Schaumburg, IL, USA, 2018.

2. Feldmann, M.; Kaspar, R.; Abeln, B.; Gessler, A.; Langosch, K.; Beyer, J.; Schneider, J.; Schula, S.; Siebert, G.; Haese, A.; et al. Guidance for European Structural Design of Glass Components; EUR 26439; JRC86637; Publications Office of the European Union: Luxembourg, 2014.

3. Behr, R.A.; Belarbi, A. Seismic Test Methods for Architectural Glazing Systems. Earthq. Spectra 1996, 12, 129-143. [CrossRef]

4. Memari, A.M.; Behr, R.A.; Kremer, P.A. Seismic Behavior of Curtain Walls Containing Insulating Glass Units. J. Arch. Eng. 2003, 9 , 70-85. [CrossRef]

5. Khoraskani, R.A. Seismic behavior of glass curtain walls. In Advanced Connection Systems for Architectural Glazing; Springer: Cham, Switzerland, 2015; pp. 33-52.

6. Gorenc, B.; Beg, D. Curtain wall façade system under lateral actions with regard to limit states. Steel Constr. $2016,9,37-45$. [CrossRef]

7. Bârnaure, M.; Voiculescu, M. The seismic behaviour of curtain walls: An analysis based on numerical modelling. Math. Model. Civ. Eng. 2013, 9, 1-8. [CrossRef]

8. Antolinc, D.; Rajčić, V.; Zarnic, R. Analysis of hysteretic response of glass infilled wooden frames. J. Civ. Eng. Manag. 2014, 20, 600-608. [CrossRef]

9. Memari, A.; Chen, X.; Kremer, P.; Behr, R. Seismic performance of two-side structural silicone glazing systems. J. ASTM Int. 2006, 3, 10. [CrossRef]

10. Memari, A.M.; Fisher, S.; Krumenacker, C.; Broker, K.A.; Modrich, R.-U. Evaluation of the Structural Sealant for Use in a Four-Sided Structural Sealant Glazing Curtain-Wall System for a Hospital Building. J. ASTM Int. 2012, 9, 1-16. [CrossRef]

11. Memari, A.M.; Kremer, P.A.; Behr, R.A. Seismic Performance of Stick-Built Four-Side Structural Sealant Glazing Systems and Comparison with Two-Side Structural Sealant Glazing and Dry-Glazed Systems. Adv. Civ. Eng. Mater. 2012, 1, 103159. [CrossRef]

12. Memari, A.M.; Chen, X.; Kremer, P.A.; Behr, R.A. Prediction of Seismic Failure of Silicone Sealant in Two-Sided Structural Sealant Glazing Systems. J. Arch. Eng. 2012, 18, 16-26. [CrossRef]

13. Memari, A.M.; Shirazi, A.; Kremer, P.A.; Behr, R.A. Development of Finite-Element Modeling Approach for Lateral Load Analysis of Dry-Glazed Curtain Walls. J. Arch. Eng. 2011, 17, 24-33. [CrossRef]

14. Simmons, N.C.; Memari, A.M. Development of Kinematic Equations for Racking Performance Evaluation of Four-sided Structural Sealant Glazing Curtain Wall Systems. In Proceedings of the 2013 Architectural Engineering Conference, University Park, PA, USA, 3-5 April 2013; pp. 997-1006.

15. Caterino, N.; Del Zoppo, M.; Maddaloni, G.; Bonati, A.; Cavanna, G.; Occhiuzzi, A. Seismic assessment and finite element modelling of glazed curtain walls. Struct. Eng. Mech. 2017, 61, 77-90. [CrossRef]

16. Memari, A.; Shirazi, A.; Kremer, P. Static finite element analysis of architectural glass curtain walls under in-plane loads and corresponding full-scale test. Struct. Eng. Mech. 2007, 25, 365-382. [CrossRef]

17. Weggel, D.C.; Zapata, B.J. Laminated Glass Curtain Walls and Laminated Glass Lites Subjected to Low-Level Blast Loading. J. Struct. Eng. 2008, 134, 466-477. [CrossRef] 
18. Quaglini, V.; Cattaneo, S.; Biolzi, L. Numerical assessment of laminated cantilevered glass plates with point fixings. Glas. Struct. Eng. 2020, 5, 187-204. [CrossRef]

19. ASTM. Standard practice for determining load resistance of glass in buildings. In ASTM E1300-16; ASTM: West Conshohocken, PA, USA, 2016.

20. Soules, J.G.; Morse, S.M.; Norville, H.S. Application of the Glass Failure Prediction Model to Flat Odd-Shaped Glass Using Finite-Element Modeling. J. Arch. Eng. 2020, 26, 04020037. [CrossRef]

21. Morse, S.M. New provisions in ASTM E1300-16: A comparison of the basic and new analytical procedures for determining the load resistance of window glass. In Vol. 2 of Proc., Façade Tectonics 2018 World Congress; De Kensek, N.K., Elder, M., Eds.; Tectonic: Los Angeles, CA, USA, 2018; pp. 529-541.

22. Simmons, N.C.; Memari, A.M. Racking Performance Analysis of Four-sided Structural Sealant Glazing Curtain Wall Systems through Video Capture Technique. In Proceedings of the 2013 Architectural Engineering Conference, University Park, PA, USA, 3-5 April 2013; pp. 725-734.

23. Simmons, N.C.; Memari, A.M. Finite Element Modeling to Predict Racking Test Results and Performance of Four-sided Structural Sealant Glazing Curtain Wall Systems. In Proceedings of the 2013 Architectural Engineering Conference, University Park, PA, USA, 3-5 April 2013; pp. 735-744.

24. Memari, A.M.; Simmons, N.; Solnosky, R.L. Unitized curtain wall systems joint performance with re-entrant corners under seismic racking testing. J. Build. Eng. 2021, 40, 102715. [CrossRef]

25. Simmons, N. Analytical Evaluation of Racking Performance of Four-Sided Structural Silicone Glazing Curtain Wall Sys-Tems. MS Thesis, The Pennsylvania State University, University Park, PA, USA, 2011. Available online: https:/ / etda.libraries.psu.edu/ paper/12618/ (accessed on 10 March 2019).

26. Memari, A.; Simmons, N.; Solnosky, R. Video Capture Technique Analysis of Four-Sided Structural Sealant Glazing Curtain Wall Systems for Racking Performance. Int. J. Arch. Eng. Constr. 2018, 7, 1-16. [CrossRef]

27. Memari, A.M.; Hartman, K.H.; Kremer, P.A. Racking Test Evaluation of EN-WALL 7250 Unitized Curtain Wall System with 3M ${ }^{\mathrm{TM}}$ $V H B^{\mathrm{TM}}$ Structural Glazing Tape; 3M Industrial Adhesives \& Tapes Division: St. Paul, MN, USA, 2011; 72p. 